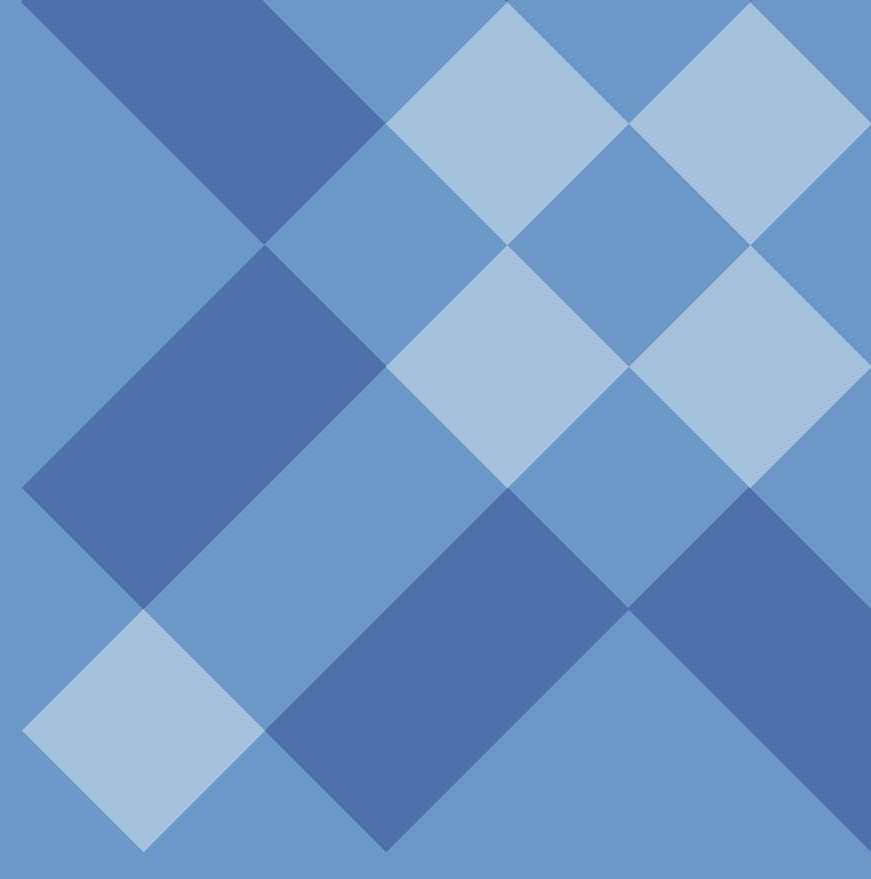

\title{
3rd PNAE Congress on Paediatric Nursing 2016
}

Beyond borders: Best practice in Nursing Children and Young People

May 26 \& 27 - Porto, Portugal

Abstracts Book Organized and peer reviewed by: Maria do Céu Barbieri Fiona Smith Sandra Cruz Jane Coad Cândida Pinto Ivona Mikulenkova Caroline Roberts-Quast Margarida Reis Santos

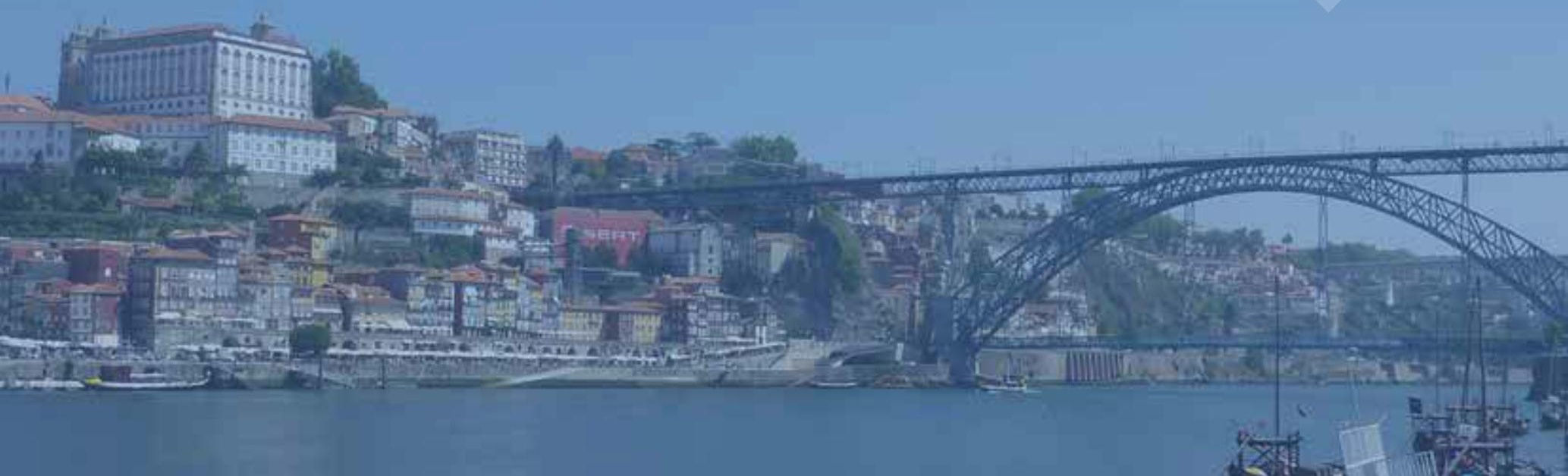




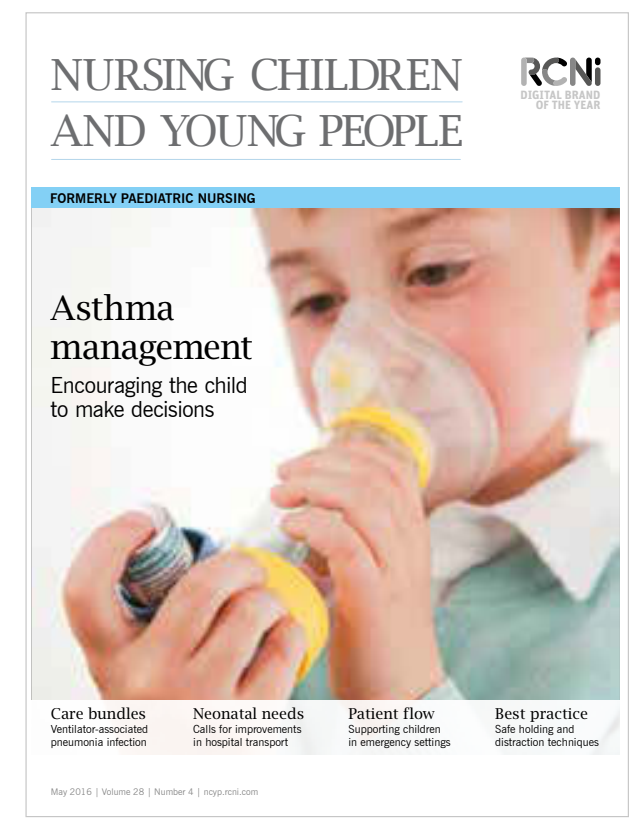

\section{PNAE}

\section{NURSING CHILDREN AND YOUNG PEOPLE}

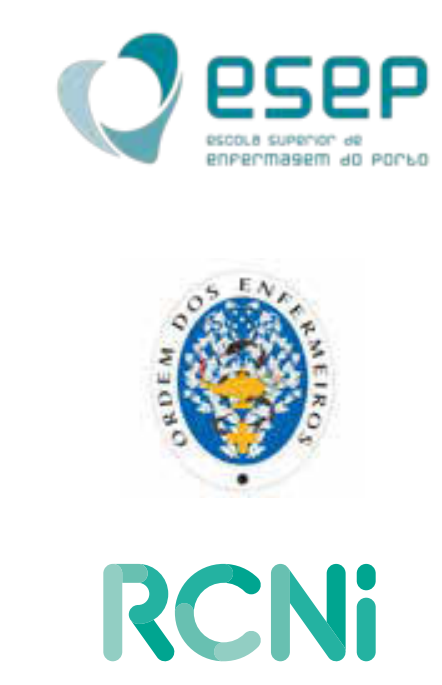

Published for The Paediatric Nursing Associations of Europe by RCNi, part of the Royal College of Nursing Group, available online through Nursing Children and Young People at ncyp.rcni.com 


\section{Welcome to the PNAE Congress 2016}

Dear colleagues,

We are delighted to welcome you to the 3rd PNAE congress on Paediatric Nursing organised by the Paediatric Nursing Associations of Europe in collaboration with Escola Superior de Enfermagem do Porto (ESEP) and Ordem dos Enfermeiros (OE).

We have joined forces to promote the sharing of knowledge and experience with the aim of enhancing paediatric nursing care across Europe. The scientific programme will include distinguished keynote speakers from countries across Europe, as well as oral and poster presentations from paediatric and neonatal nurses who will share with us their research findings, service improvements, empirical knowledge and experiences regarding the care of infants, children, young people and their families.

We owe particular thanks to ESEP and to OE for their support in enabling this congress to be held at ESEP - Portugal.

We anticipate that paediatric nurses from across Europe will attend this congress to enrich their knowledge and to hear about the latest developments in the care of children, young people and their families. The congress will provide the opportunity to network, share ideas and learn from colleagues about improving the care and outcomes for infants, children and young people.

We look forward to welcoming you to the vibrant city of Porto and hope you have an enjoyable and fruitful stay.

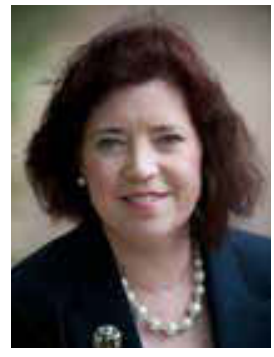

Fiona Smith Chair: Conference Organising Committee

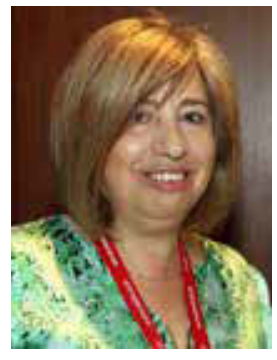

Maria do Céu Barbieri Chair: Conference Scientific Committee 
Keynote speaker abstracts 


\section{Edel Kirketerp \\ Chief nurse, paediatric department, Kolding Hospital, Kolding, Denmark}

\section{What matters to you?}

We asked the children, their families and the staff and found so much hidden but useful and valuable information in creating a new ward for children.

I hope in my subject for this PNAE 2016 Congress to show how innovation and involvement can inspire children, parents and staff as co-designers together with professional designers, anthropologists, builders and supporters to create an inspiring children's ward.

Our challenge was that all the children from age 0-17 years would feel comfortable in the different situations that occur during a hospital-stay.

Small children (0-3 years) require surroundings where they can play safely close to their parents.

Children aged from 4 to 12 years require surroundings where they can explore 'the whole world' with or without their parents. This age group loves activities such as climbing, running and biking.

Young people from 13-17 years want privacy, with access to computers, smartphones, music and time with friends. Their parents play a minor role in their lives.

When we asked children and young people to pick a ward-theme from six choices, including Cyber-space, Water-world, Circus, Forest with animals, they all wanted Forest with animals. When we asked the parents and staff, we got the same answer.

As the theme was set, we started a two-year journey with a fixed goal, but we didn't know exactly how to reach that goal.

Our challenge was that we still had to function as a children's hospital while it was renovated and extended by $800 \mathrm{~m}^{2}$. It was often difficult for the professionals to keep the children away from the construction areas and dangerous machinery. The builders sometimes invited the children and parents to watch while they worked, which was helpful for staff as it gave the children funny experiences to enjoy.

Three years have passed since the official opening of the ward, and we still love it and are so proud to welcome and admit the children to these surroundings.

In the first year we had more than 20 visits from other hospitals, committees, builders and designers who wanted to be inspired by this innovative way of creating ideas with hospital consumers and staff.

I hope my speech inspires other European children's departments to innovate and gain from the information you can collect from patients when you ask: what matters to you when we create a new ward? 
Fiona Smith

Professional lead for children and young people's nursing,

Royal College of Nursing, United Kingdom and co-ordinator of the Paediatric

Nursing Associations of Europe

\section{Priorities for children and young people - opportunities and challenges for children and young people's nurses}

Across Europe children's nurses today face many challenges, including rising childhood obesity, the soaring incidence of issues with the mental health of children and young people, the effects of social media, child maltreatment and the impact of poverty, war and conflict on children and families. There are opportunities for children's nurses to undertake new roles and to influence both policy and practice to improve the health outcomes of children and young people, and thereby the future health of the population.

The role of children's nurses continues to expand in response to the changing healthcare needs of children and young people. Nursing roles have developed to maximise the use of nursing knowledge and skills in the delivery of healthcare services. Children's nurses provide care across many settings and not just in traditional children's wards, but in social care and education settings, as well as in children's own homes. Today children's nurses in many countries work in a variety of ways to enable children with complex healthcare needs, for example, to be cared for at home, support parents in the early years of a child's life and provide palliative care, symptom management and end of life care to enable a child to live as near a normal life as possible and to die at home. Children's nurses working in advanced roles assess, diagnose, treat, prescribe and discharge patients independently. Specialist children's nurses may undertake surgical pre-assessment and provide complete follow-up care to children with long-term conditions such as asthma and eczema. Other senior and experienced practitioners spend some of their working week as part of medical rotas in highly technical and specialist areas, such as neonatal and children's intensive care, while others in nurse consultant roles may lead entire teams in the provision of a service for children on long-term ventilation.

The presentation will highlight key challenges for children's nurses today, drawing upon examples to demonstrate the changing role of children's nurses, as well as to highlight differences across Europe. The work of the Paediatric Nursing Associations of Europe will also be highlighted and the need to learn from each other to achieve improvements in children and young people's health outcomes. 


\title{
'Touchpoints' by nurses: impact on maternal representations, child development, quality of mother-infant interaction, and mothers' perception of the quality of relationships with nurses
}

\begin{abstract}
Aim: To investigate the effect of implementing the Touchpoints methodology by nurses in the following variables: quality of mother-infant interaction; infant development; maternal representations of child temperament and mothers' perception of the quality of relationship with nurses.
\end{abstract}

\begin{abstract}
Methods: Quasi-experimental longitudinal study, including 86 child-mother dyads distributed equally for: Group with Intervention (GI) (n=43), Group without Intervention (GWI) (n=43). These groups belonged to paired samples according to the following criteria: maternal age; socio-economic class; family structure; child health; parents' physical or psychological health; twins; family's nationality; risk during pregnancy; baby APGAR. Paired samples with the same routine visits allowed comparing the impact of Touchpoints intervention on the above mentioned variables. The monitoring of the two groups took place in a period of between 11 and 24 months of children's life (four moments of assessment), being held two Touchpoints sessions in the Gl at 12 and 18 months. Two Touchpoints interventions sessions were applied in the $\mathrm{Gl}$ as follows: the first time, at 12 months; the second time, at 24 months, child age.
\end{abstract}

The instruments used for data collection were: Schedule of Growing Skills II (SGS II); CARE-Index; Temperament Scale; Parent-Caregiver Relationship Scale - parents' version.

Results: Infant Locomotor development $(\mathrm{p}=.036)$ and maternal representations about the child and motherhood ( $Z=5.737 ; p=.019)$ improved in the Gl. No significant results were found for mother-infant interaction in this direct comparison. Nevertheless, findings indicate that maternal sensitivity and infant cooperative behaviour increased from 12 to 24 months in the Gl [t(41)=4.513; $p<.001$, whereas it decreased in the GWI (from 8.62 at 12 months to 8.40 at 24 months). The means of mothers' perceptions of Trust/Caring towards nurses in the $\mathrm{Gl}$ were higher than in $\mathrm{GWI}$ after six months of the Touchpoints intervention $[\mathrm{t}(84)=2.146$; $\mathrm{p}<.001 ;$ M_Gl=34.07, SD=3.71; M_GWl=31.79], Collaboration/Partnership [t(84)=2.817; $\left.\mathrm{p}<.001 ; \mathrm{M} \_\mathrm{Gl}=62.79, \mathrm{SD}=4.809 ; \mathrm{M} \_\mathrm{GW}=59.89, \mathrm{SD}=6.538\right]$ and Relational/Emotional $\left[t(84)=2.334 ; p<.001 ; M \_G l=60.53, S D=3.838 ; M \_G W I=58.30, S D=5.638\right]$.

Children at risk for developmental problems in the GI and GWI improved their development in Speech and Language $\left(Z=4.772 ; p<.05 ; M \_G l\right.$ at risk $=13.64 \mathrm{SD}=.30$ vs. M_GWl at risk=13.00, $S D=.29)$, Hearing and Language $\left(Z=4.341 ; p<.05 ; M \_G l\right.$ at risk=15.08, $\mathrm{SD}=.37$ vs M_GWl at risk=14.0, $S D=.36)$ and in Self-care Social $(Z=4.0 ; p<.05$ vs M_Gl at risk=11.96, $S D=.35 ;$ M_GWI at risk=11.46, $S D=.34)$ after the intervention with Touchpoints. Also, maternal sensitivity and infant cooperative behaviour increased after Touchpoints intervention in dyads of 'children at risk' for developmental problems when compared to the dyads of 'children at risk without' these problems.

Conclusion: The intervention using Touchpoints methodology by nurses had a positive effect on the following dimensions: infant development; maternal representations about the child and motherhood; maternal sensitivity and infant cooperative behaviour; perceptions of Trust/Caring towards nurses. This was particularly significant among children who were identified as having potential development risks. Further research is needed to better explain these findings. 


\section{The power of early interventions in families with preterm born children}

The Tromsø Intervention Study on Preterms (TISP) started in 1999 and we may now present results on children's socio-emotional and behavioural development, parental wellbeing and perceptions of the children's quality of life until children's age of nine.

Infants born preterm from the northernmost part of Norway (birth weight $<2000$ grams) were randomly selected to a premature intervention group ( $\mathrm{PI}, \mathrm{N}=72)$ and a premature control group (PC, $N=74$ ); 75 healthy newborns formed a term control group (TR). The intervention, a modified version of The Mother-Infant Transaction Program (MITP-M), included eight hours of supervision for the mother (and father if present) the last week in the $\mathrm{NICU}$ and four home visits about seven, 14, 30 and 90 days after discharge. The aim of the MITP-M was to strengthen parents' enthusiasm for their child and help them recognise signs of children's organization versus need for regulatory support. Furthermore, to show parents appropriate interactions with the child that would minimize child disturbance and increase interactional satisfaction for all partners. All families were followed up through developmental tests of children and responses to questionnaires at children's age of six months, one, two, three, five, seven and nine years. The main aim was to analyze whether differences between the $\mathrm{Pl}$ and the PC group emerged as a possible consequence of the intervention. The PI and the PC group were in addition compared with the results of the TR group.

Longitudinal analyzes showed that the average prevalence of behavior problems varied according to the same pattern in the three study groups from two to nine years. PC mothers and PC fathers reported slightly more behavior problems than PI-parents who had received the intervention at all follow-ups, even not creating significant differences between $\mathrm{Pl}$ and PC. No longitudinal differences were detected in longitudinal behavior development between the intervention group and the term control group, but one was detected between the PC and the TR group. Fathers in the PC group reported a steeper increase in symptoms of anxiety in their preterm-born children from their age of five until nine years compared with fathers of term-born children.

Significant differences between the PI and the PC group became visible at children's age of seven and nine years where both parents and teachers reported significantly less attentional problems and better social competence, adaptability and school-related performances in the PI group. PI children were in average reported as similar to the TR group at the age of nine, both what came to school adjustment, achievements and the occurrence of problems. Significant differences between the PC and the TR group persisted concerning both behavior problems and competencies. The presentation will also document how the intervention may have strengthened parents and children's wellbeing. The research presented in this presentation indicate that the structured guidance given parents of preterms in the newborn period has promoted positive and long-lasting effects on the PI group as these children perform at similar level as their term-born peers at nine years of age. 


\section{Orsola Gawronski \\ Registered nurse, certified in paediatrics, Bambino Gesù Children's Hospital (BGCH) IRCCS}

\section{Evidence-based paediatric nursing: paediatric early warning systems}

In hospital cardiac arrest are rare events in paediatrics. Most children receive appropriate care without experiencing undetected severe clinical deterioration during hospital admission. Outcomes of paediatric cardiac arrests are however generally poor, with high mortality rates and neurological damage at survival. A review of child mortality in the UK showed that a high proportion of unexpected deaths were preventable (Pearsons 2008). Several studies of patient records of children who suffered cardiac arrests showed the presence of clear signs of clinical deterioration up to 24 hours before (Tume 2006). Appropriate recognition of clinical deterioration could have led to timely intervention to stabilise the patient. Missed deterioration may be due to lack of staff situational awareness, communication failure among professionals or between staff and families and other human factors (Brady 2014).

In a healthcare environment with increasing complexity of care and limited resources, early warning systems are wide spectrum complex interventions designed to increase patient safety and improve resource utilisation in the hospital setting. Their application is described in the paediatric setting since 2005. Their concept is derived from experience in the adult population. There are several paediatric alert criteria published, but so far there's no consensus on the system to be used. The absence of rigorous testing to support validity and reliability is a key issue. So far the best available testing has been performed on the BedsidePEWS though a multicenter study on more than 2,000 patients (Parshuram 2011). The main domains considered for single parameter or aggregated weighed alert criteria are respiratory, cardiovascular and consciousness clinical indicators. Most systems refer mainly to objective indicators such as heart rate, respiratory rate, systolic blood pressure or transcutaneous blood saturation. Subjectively assessed clinical indicators are also often included, such as work of breathing, capillary refill time, skin colour, parental and staff concern. Due to age-related variability of vital signs in the paediatric population most systems use age-specific groupings and thresholds to identify clinical deterioration (Chapman 2010). Consensus on vital signs cut-offs is also weak and consequently variability between systems occurs.

The aim of early warning scores is to identify children that deteriorate to provide appropriate interventions and prevent adverse outcomes. Response algorithms include increased patient monitoring, medical and nursing assessments, nurse patient ratios and Rapid Response Team (RRT) involvement. Benefits such as reduced PICU urgent admissions and reduced PICU interventions in admitted patients are described. However, the available evidence of impact of PEWS on clinical outcomes is still weak. The EPOCH study is so far the first clinical trial that aims to investigate the efficacy of a paediatric early warning system on mortality, processes of care and resource use (Parshuram 2015). Other benefits are related to improved staff communication and nursing empowerment to initiate escalation of care or call the RRT.

Implementation requires staff buy in by focusing on the system's rationale, staff education and the system integration in the current hospital processes of care. Continuing process monitoring is needed to identify gaps in the implementation. Poor compliance with documenting vital signs and response to high-risk patients may weaken the system's potential for preventing serious adverse events. 


\section{Bibliography}

Brady PW, Goldenhar LM (2014) A qualitative study examining the influences on situation awareness and the identification, mitigation and escalation of recognised patient risk. BMJ Quality and Safety. 23, 153-161

Chapman SM, Grocott MP, Franck LS (2010). Systematic review of paediatric alert criteria for identifying hospitalised children at risk of critical deterioration. Intensive Care Medicine, 36, 4, 600-11.

Pearson GA (Ed) (2008) Why children die: A pilot study 2006; England (SW, NE \& W Midlands), Wales \& N Ireland. London $\mathrm{CEMACH}$.

Tume L (2007) The deterioration of children in ward areas in a specialist children's hospital. Nursing in Critical Care. 12, 12-19.

Parshuram CS, Duncan HP, Joffe AR, Farrell CA, Lacroix JR, Middaugh KL et al. Parkin, PC (2011). Multicentre validation of the bedside paediatric early warning system score: a severity of illness score to detect evolving critical illness in hospitalised children. Critical Care, 15(4), R184.

Parshuram CS, Dryden-Palmer K, Farrell C, Gottesman R, Gray M, Hutchison JS et al For the Canadian Critical Care Trials Group. (2015). Evaluating processes of care and outcomes of children in hospital (EPOCH): study protocol for a randomized controlled trial. Trials. 16, 245. 


\author{
Veronica Lambert \\ School of nursing and human sciences, Dublin City University, Ireland
}

\title{
Design of paediatric hospitals
}

The impact of healthcare environments on children and young people's (CYP) health and psychosocial wellbeing has attracted much attention in recent years. This sits within the realm of the political drive for enhanced awareness of the need to take account of the rights and voice of the child. Perhaps as a direct result of the United Nations Convention on the Rights of the Child, and recognition from evidence in adult population studies of the impact of healthcare environments on psychosocial healing, contemporary times have witnessed a discernible movement towards enhancing quality care by promoting child and adolescentfriendly hospital environments. The Council of Europe guidelines on child-friendly health care moved to place the rights and needs of children at the heart of health care. The Council acknowledges that the delivery of child-oriented services, which includes the notion of family-centred care, should be delivered in child and family friendly environments. However, knowledge about what constitutes a child-friendly healthcare environment from CYP's perspective is often lacking with hospital architectural blueprints predominantly designed around adult proxy-reported assumptions about the needs and desires of children.

CYP's opinions must be taken into account by hospital environmental design planners if healthcare spaces aspire to being CYP and family friendly. This is important because previous evidence has demonstrated that children's priorities and preferences for hospital design may differ to those of adults. The content of this presentation has been informed by previous participatory art-based work that investigated young children's (aged five to eight years) perspectives of hospital physical places and social spaces to inform the design of the built environment of a new children's hospital; alongside the conduct of a scoping review of the literature with a particular focus on studies examining CYP's perspectives of hospital environmental design. Core themes that will be discussed include first impressions and architectural scale on entering the hospital building; entrapment, way finding, free movement and having a sense of space; entertainment, socialisation and connectivity; communal, family, personal and private spaces; having access to the outside world; and a preference for interior designs that are aesthetically pleasing and epitomise modern, creative, colourful, imaginative and comfortable décor.

These themes are important for nurses, clinicians' environmental designers, policymakers and other stakeholders to consider because they represent what a supportive child healthcare environment should constitute from the perspective of children themselves. A challenge for hospital environmental designers is how to ensure CYP's voices are translated into the hospital architectural blueprint, as many factors can impede the creation of an ideal child-friendly hospital environment; most notably, the desire to meet the wishes of multiple stakeholders. A key recommendation for clinicians caring for CYP in hospital is to find ways to appropriately enact an environment that promotes CYP's independence and locus of control. 


\section{Jane Coad}

Professor in children and family nursing, director of children and families research, and associate dean of research at Coventry University, UK

\section{Through the lens of young people: use of photography in hospital design}

Whilst arts in hospitals have been perceived as therapeutic to patients, this paper will share evidence and research to support that photography and photo-elicitation has an important role in preference and choice about hospital design. The paper will initially draw on studies that used participatory photography in children's hospital design in international settings.

More specifically, this keynote presentation will share the use of participatory photography to empower young people to influence and shape hospital designs, thus resulting in design by young people for young people. A study will be shared that was undertaken by the author in the UK, which included data collection techniques of photo-elicitation and photo-interviews within a hospital-based young people's advisory group. Interviews centred on supporting young people to review and react to sets of photographs in order to explore hospital design preference. Data analysis was iterative and data sets were compared to wider literature and evidence in the field.

Strengths and limitations of participatory photography will be shared. This study was interesting as it provided an in-depth exploration of young peoples' responses to the set of photographs. But even more interesting was that through the method, it provided young people with an opportunity to engage in an enjoyable activity, but gave them a platform to have choice and voice in their hospital design. 
Abstracts of concurrent sessions 


\title{
OC01 - The effect of an Interactive Therapeutic Play Training Program on the anxiety levels of children having heart surgery and their mothers
}

\author{
Ayşegül Elmas Coşantürk (Turkey); Duygu Gözen (Turkey)²
}

\begin{abstract}
${ }^{1}$ Kartal Koşuyolu High Specialized Education and Research Hospital; ${ }^{2}$ Istanbul University Florence Nightingale Faculty of Nursing
\end{abstract}

Theme: Child protection and managing risk.

Keywords: Anxiety, Beck Anxiety Inventory, congenital heart disease, therapeutic play.

Research was conducted using randomized controlled and experimental methods in order to determine the impact of Interactive Therapeutic Play Training Program applied for preparation of children's heart disease operation on child's and mother's post-operative anxiety levels. The sample consisted of 23 experimental and 20 control child-mother pairs who were hospitalized between April-September 2015 with Congenital Heart Disease in the six to 12 years age group. The day before the operation, children in the experimental group with their mother were given 'Interactive Therapeutic Play Education Program'. Data was obtained with an Information form, Anxiety Inventory for Children and Beck Anxiety Scale.

Results: $55 \%$ of children were girls, while $100 \%$ of them were primary school students. As a result, anxiety levels of children and mothers in the preoperative period were similar, whereas in the postoperative period State Anxiety Inventory for Children and Beck Anxiety Inventory scores for the experimental group were found to be lower than control group $(\mathrm{p}<\cdot 0,05)$.

\section{OC02 - Promoting the university research of paediatric nurses}

\author{
Madeleine Collombier (France) ${ }^{1}$; Emilie Courtois (France) ${ }^{1}$; \\ Karine Renaudie (France) ${ }^{1}$; Catherine Thomyre (France ${ }^{1}$
}

\begin{abstract}
${ }^{1} A N P D E$
Theme: Nursing education, management and leadership.

Keywords: Paediatric nursing education, research, scientific publication.

While training to obtain a university degree in addition to the state paediatric nursing diploma, French paediatric nurses conduct research studies, which are not identified nor highlighted.
\end{abstract}

We aim to create a network of paediatric nurses with a university degree, in order to highlight their research.

We conducted a national survey, with questionnaires from June to December 2013, to numerate paediatric nurses with university degrees. Sixty-six paediatric nurses with at least one university degree responded. The more frequent diploma was a one-year university degree in the area of nursing; three studies out of 72 have been published. 
This study has shown French paediatric nurses have a university background and are engaged in nursing research. This research remains too little known (4.2\% published). Support and encouragement of paediatric nurses to publish is needed to achieve the goal of evidence-based practice.

\title{
OC03 - Multiple employment: perceptions of nurses regarding the quality of nursing care
}

Vanessa Costa (Portugal) ${ }^{1}$

\author{
${ }^{1}$ Hospital Cuf Torres Vedras
}

Theme: Accreditation and quality improvement.

Keywords: Multiple employment, quality of care, nursing care.

Objectives: To identify factors related to multiple employment that nurses consider as an influence to the care provided; analyze the perceptions of nurses regarding the influence that these factors have on quality of care provided.

Methods: The study is a qualitative study, with a sample of 17 nurses, seven currently working in multiple employments, five who have worked in multiple employments but currently do not, and five who have never worked in context.

Conclusions: The majority of nurses who have worked in multiple employment and those who have never worked in multiple employment consider that there are negative implications for the quality of care when a nurse is working in a multiple employments context. However, most of the nurses working in multiple employments do not consider it as the direct cause for the implications in the quality of care, because fatigue can have different precipitating factors, whether social, family, psychological or emotional.

\section{OC04 - A weaning plan for high flow nasal therapy (HFNT) in bronchiolitis - a nurse-led initiative}

Claire Colvine (United Kingdom) ${ }^{1}$; Laura McCulloch (United Kingdom) ${ }^{2}$; Calum Morrison (United Kingdom)2; Mandy Allen (United Kingdom) $)^{1}$

${ }^{1}$ University of the West of Scotland; ${ }^{2}$ NHS Ayrshire and Arran

Theme: Nursing education, management and leadership.

Keywords: Bronchiolitis, high flow nasal therapy (HFNT), weaning plan.

Introduction: The use of HFNT in bronchiolitis is a new phenomenon in paediatrics, with insufficient evidence on its effectiveness (Beggs et al 2014). This paper reports the findings of a clinical audit which resulted in the development of a nurse-led weaning plan to support infant recovery with the potential to reduce hospital stay.

Objective: To highlight the effectiveness of a nurse-led weaning plan in a general paediatric unit. 
Method: The data of 32 infants were analysed between October 2014 and March 2015. Further data will be collected between October 2015 and March 2016. Data will then be compared.

Results: Initial data demonstrates the average time infants spent on HFNT was 2.6 days compared to five days in previous studies (Bressan et al 2013).

Discussion: A nurse-led weaning plan has been developed from data collected.

Conclusion: The audit demonstrates a clinical need for efficient weaning of infants on HFNT.

\section{OC05 - Tokenism or true partnership - parental involvement in a child's acute pain care}

Jackie Vasey (United Kingdom)ㄹ; Joanna Smith (United Kingdom); Marilynne Kirshbaum (Australia) ${ }^{3}$; Kathleen Chirema (United Kingdom $)^{1}$

${ }^{1}$ University of Huddersfield; ${ }^{2}$ University of Leeds; ${ }^{3}$ Charles Darwin University

Theme: Parenting/parenthood.

Keywords: Acute, child, involvement, pain, parent.

Introduction: Family-centred care (FCC) is widely acknowledged as underpinning children's nursing. Delivering FCC requires nurses to advocate for family involvement, particularly in areas where evidence suggest the child's needs are not being met, such as pain care.

Aim: To explore parental involvement in their child's acute pain care.

Methods: A qualitative ethnographical approach was adopted, with non-participant observation and follow-up interviews. The framework approach underpinned data analysis.

Results: Partnership between nurses and parents is not overtly evident in relation to pain care. Involvement is often 'unspoken', indicating that neither the nurse nor parent are clear about the extent to which parents can, or are, involved in care.

Discussion: Parents want greater involvement in their child's pain care and often initiate involvement by advocating for their child, with or without support from nurses.

Conclusions: The 'Pillars of Partnership in Pain Care' model offers an alternative approach to involving parents.

\section{OC06 - Involving parents in their child's care - where next?}

Joanna Smith (United Kingdom)i; Veronica Swallow (United

Kingdom $)^{1}$; Imelda Coyne (Ireland) ${ }^{2}$

${ }^{1}$ University of Leeds; ${ }^{2}$ Trinity College Dublin

Theme: Complex health care and chronic disease management. 
Keywords: Collaboration, family-centred care.

Introduction: Health policy advocates that professionals involve parents in care and care decisions, yet models advocating involvement are not embedded into practice.

Aim: Identify the shared antecedents and key attributes associated with embedding family-centred care (FCC) and partnership-in-care (PiC) into practice.

Methods: A concept synthesis was undertaken by searching three databases (Scopus, CINAHL, BNI 1999-2014); shared antecedents and attributes were extrapolated from the 30 studies that met defined inclusion criteria.

Results: Unclear roles and boundaries, entrenched professional practices and lack of guidelines hinder FCC/PiC implementation. An alternative framework was developed based on the actions and skills required to support parents' involvement in care and care decisions.

Discussion: Greater focus on the skills required to facilitate involvement may negate the challenges of embedding FCC /PiC.

Conclusion: The framework for involvement can help guide nurses' actions towards building effective relationships and involving parents in care decisions.

\title{
OC07 - Why should parents and health professionals collaborate to manage childhood long-term conditions?
}

\author{
Joanna Smith (United Kingdom); Sarah Kendal (United Kingdom)²
}

\section{${ }^{1}$ University of Leeds; ${ }^{2}$ University of Huddersfield \\ Theme: Complex health care and chronic disease management}

Keywords: Childhood long-term conditions, collaboration

Introduction: Interactions between carers and health professionals often have a power imbalance; professionals seem reluctant to acknowledge carers' expertise and unwilling to relinquish control over the management of the child's condition.

Aim: To explore parents' and professionals' perceptions of collaborative healthcare practice to manage childhood long-term conditions.

Methods: Qualitative study using focus groups to elicit carers' and health professionals' views of collaborative practice, with the framework approach underpinning data analysis.

Discussion: To facilitate parents' care-giving roles, health professionals must move from a position of care prescriber to collaborator. Yet collaboration is complex and difficult to operationalise in practice, partly because there is discordance between the views of health professionals and carers about the purpose of collaborating.

Conclusion: Health professionals need to understand, value and respect carers' expertise and desire to be involved in care and find ways to integrate carer expertise into care and care planning. 


\section{OC08 - Care for the children with severe forms of atopic dermatitis}

Ivona Mikulenková (Czech Republic)'; Miroslav Kobsa (Czech

Republic) ${ }^{1}$; Jana Mičková-Domitrová (Czech Republic) ${ }^{1}$

${ }^{1}$ Hospital Nový Jičín

Theme: Complex health care and chronic disease management.

Keywords: Apheresis, atopic dermatitis, immunoglobulins, immunoadsorption

Fast progress in medicine brings new development and new methods in treatment for children and youth with atopic dermatitis.

There is an increasing number of children with this disease and in some cases the available treatment is failing. In our hospital we offer new methods of treatment for this group of patients.

Objectives:

- describe the whole process of selecting patients for particular treatment

- analyse our unit experience and identify advantages and barriers in the process

- evaluate the results of specific treatments

- gain insight of family experience

- European statistics of the patients receiving treatment of immunoadsorption.

Methods:

- standard questionnaire given to the families

- research and co-operation with the European centres.

Results and conclusion

- European statistical results are still in process of evaluation

- further development of our services

- there are clear benefits to the children

- development of system to make particular treatment more accessible.

\section{OC09 - Early maternal contact has an impact on preterm infants' brain systems that manage stress}

Evalotte Mörelius (Sweden)ㄹ; Annika Örtenstrand (Sweden)²; Elvar Theodorsson (Sweden) ${ }^{3}$; Anneli Frostell (Sweden) ${ }^{3}$

${ }^{1}$ Linköping University Department of social and welfare studies; ${ }^{2}$ Karolinska Institutet; ${ }^{3}$ Linköping University 
Theme: Parenting/parenthood.

Keywords: Kangaroo mother care, neonatal intensive care, parents, stress.

Introduction: Early maternal contact can protect the infants' brain from harmful effects of stress while deprivation increases the stress level and leads to increased sensitivity to stress.

Aim: To evaluate the effects of continuous skin-to-skin contact (SSC) after preterm birth on stress.

Methods: Late preterm infants from two neonatal care units were randomized to either SSC or standard care. Salivary cortisol was measured in response to a nappy change at one month, and again at four months in response to a still-face procedure.

Results: Infants randomized to SSC had a significantly lower salivary cortisol reactivity at one month and there was a correlation between the mothers' and the preterm infants' salivary cortisol levels at four months.

Conclusions: The results show that close parental contact and human touch have a buffering effect on the infant's stress reactivity and stimulate a more rapid development of regularity.

\title{
OC10 - Inter-rater agreement of the Paediatric Early Warning Score tools used in the central Denmark region
}

\author{
Claus Sixtus Jensen (Denmark) ${ }^{1,2}$; Hanne Aagaard (Denmark); \\ Hanne Vebert Olesen (Denmark) ${ }^{3} ;$ Hans Kirkegaard (Denmark) ${ }^{1}$
}

\author{
${ }^{1}$ Research Center for Emergency Medicine, Aarhus University Hospital; ${ }^{2}$ Aarhus \\ University; ${ }^{3}$ Department of Paediatrics, Aarhus University Hospital
}

Theme: Patient safety

Keywords: Inter-rater agreement, Paediatric Early Warning Score, PEWS, reliability.

Background: Paediatric Early Warning Score (PEWS) tools can assist healthcare providers in the rapid detection and recognition of changes in patient condition. In the central Denmark region two different PEWS tools tested in large-scale RCT study. However, data from PEWS instruments are only as reliable and accurate as the caregiver who obtains and documents the parameters.

Aim: The purpose was to evaluate the inter-rater agreement among nurses using the PEWS systems.

Design: The study was conducted in five paediatrics departments. Inter-observer reliability was investigated through simultaneous blinded PEWS assessment on the same patients by two nurses.

Fleiss' kappa was utilized to determine the level of agreement among the raters.

Conclusion: With a paucity of published reliability testing studies, this research attempts to address identified research gaps and will thus inform nursing practice. 


\section{OC11 - Social support and intervention focus to minimize the effects of oncological disease in healthy siblings}

Goreti Marques (Portugal)ํㅜㄹ Beatriz Araujo (Portugal)²

${ }^{1}$ Escola Superior de Enfermagem de Santa Maria do Porto; ${ }^{2}$ Universidade Católica do Porto

Theme: Complex health care and chronic disease management.

Keywords: Child nursing, family, impact of oncological disease in healthy siblings; social support.

Introduction: The entire process underlying cancer disease not only affects the sick child, but also the healthy siblings, which should be the centre of attention from parents and nurses.

Objectives: To identify the impact of the disease in healthy siblings and know the importance of social support to minimise its impact in healthy siblings.

Methodology: Descriptive, correlational study, a sample of 128 families of children with oncological diseases, between August 2011 and January 2013. In order to do our research we used the following tools: Assessment questionnaire of the children's oncological diseases impact on the family and Satisfaction Scale Social Support.

Results: Families with a higher impact on family structure and more accrued expenses showed greater impact of the disease in healthy siblings, the most satisfied with their social support showed less improvement.

Conclusions: Nurses should seek interventions that increase the perception of the need for social support of families.

\section{OC12 - A journey suspended in time: parents' experiences of caring for their child who is 'technology dependent' with complex ongoing healthcare needs at home}

Yvonne Corcoran (Ireland) ${ }^{1}$; Prof Owen Barr (United Kingdom)²; Dr Rosario Baxter (United Kingdom)²

${ }^{1}$ Dublin City University; ${ }^{2}$ Ulster University

Theme: Complex health care and chronic disease management.

Keywords: Caregiver, complex care, parents, technology-dependent children.

Introduction: Increasing numbers of children with complex healthcare needs who are also dependent on medical technology are surviving and being cared for at home by their parents. 
Aim: To gain an in-depth understanding of the lives of parents and the impact of their caregiver role on their family when they care for their child at home.

Method: An interpretative phenomenological design was deployed to interpret the narratives of sixteen parents through interviews and digital audio diaries.

Discussion: The complex journey parents undertake as caregivers to their child at home.

Conclusion: The understanding revealed will prompt practitioners to reflect on how to promote best practice for this group of children, their parents and their families by recognising the complexity of the care parents provide for their child and the support required in order to sustain their caregiver role at home.

\section{OC13 - Parents' support needs during and following the death of their baby}

Michaela Barnard (United Kingdom) ${ }^{1}$

\section{${ }^{1}$ University of Salford}

Theme: Complex health care and chronic disease management.

Keywords: End of life, grief, neonatal, parents, support.

Introduction: Support for bereaved parents after the death of a baby in the neonatal period is variable in the UK.

Aim: To explore parents' experiences and perceptions of support needs during and following the death of their baby.

Methods: An interpretative phenomenological study using unstructured interviews was undertaken. Analysis was undertaken using interpretative phenomenological analysis.

Results: Parental grief journeys are complicated by events experienced at the end of their baby's life. A variety of support systems are needed to facilitate parental grief journeys.

Discussion: The variation in availability of support for parents after a neonatal death needs addressing. Whilst parental need is individualised, most parents need support in some format.

Conclusions: Health professionals have a key role to play in supporting parents and signposting other supportive mechanisms after a neonatal death.

\section{OC14 - Implementation of an educational program in children's post - operative pain}

Fotini Mavridi (Greece) ${ }^{1}$; Anastasia Statiri (Greece) ${ }^{2}$;

Adelais Tsiotou (Greece)³; Evangelia Kaliardou (Greece); Anastasia Doxara (Greece) ${ }^{1}$; Vasiliki Matziou (Greece)²

${ }^{1}$ Surgical Ward, 'P\&A Kyriakou' Children's Hospital, Athens; ${ }^{2}$ National \& Kapodistrian University of Athens, Nursing Department, Athens; ${ }^{3}$ Department of Anaesthesiology, 'P\&A Kyriakou' Children's Hospital, Athens 
Theme: Nursing education, management and leadership.

Keywords: Educational intervention, paediatric pain, post-operative pain management.

Introduction: Successful pain management contributes to high-quality postoperative care.

Objective: To estimate the intensity of postoperative pain in children after an educational intervention.

Method: Surgical ward nurses after educational intervention recorded 146 children (0-16 years) postoperative pain scores, applying FLACC, FACES, NRS according to child's age during December 2012 to March 2014.

Results: The mean values of children's pain scores at the reception, $24 \mathrm{~h}$ and $48 \mathrm{~h}$ after surgery was $0,99 \pm 1,68,0,6 \pm 1,43$ and $0,13 \pm 0,79$ respectively. The median pain scores for the 1st and 2nd 24-hour seemed to correlate with the duration of surgery ( $p=0.048)$. Only $20 \%$ of cases applied some form of non-pharmacological pain method that was associated with the child's age $(p=0,001)$.

Discussion: Special care should be taken about using non-pharmacological pain control methods.

Conclusions: Postoperative pain management programs contribute to effective deal.

\title{
OC15 - Leading nursing educational progress in child mental health
}

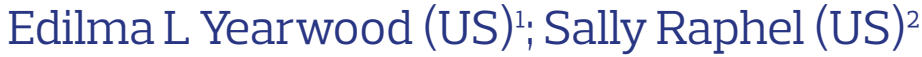 \\ ${ }^{1}$ Georgetown University School of Nursing \& Health Studies, US; ${ }^{2}$ Johns Hopkins \\ University School of Nursing, US
}

Theme: Nursing education, management and leadership.

Keywords: Child mental health, education, nurses.

Given the increasingly complex mental health needs of children and young people and the critical shortage of proficient mental health specialists, a study of US nursing education programs was done. Does the current paediatric nursing workforce preparation best meet the distinct needs of young people with behavioral and mental health challenges is the key question? Experts in the field of child psychiatric nursing practice, education and research came together to find model nursing programs for educational and clinical preparation. This presentation will report an analysis of the content of curricula-preparing psychiatric mental health nurse practitioners, models for adaptation to paediatric nurses' training and recommendations for leadership strategies.

Objectives: Describe existing US nursing education models for child and youth mental health care. Propose strategies for education leadership. 


\title{
OC16 - Calculation skills and e-learning platform: study pre-post test on students of paediatric nursing in Italy
}

\author{
Marilena Bambaci (Italy) ${ }^{1}$; Federica Vignali (Italy) ${ }^{1}$; Fulvio Ricceri \\ $\left(\right.$ Italy) ${ }^{2}$; Anna Persico (Italy)1; Maria Chiara Ariotti (Italy)'; \\ Liliana Vagliano (Italy) ${ }^{1}$
}

${ }^{1}$ University of Turin; ${ }^{2}$ Unit of Epidemiology, Regional Health Service ASL TO3

Theme: Child protection and managing risk.

Keywords: Nursing student, skill calculation, mathematical error, drug calculation, children.

Errors in medication is a very recurring problem in paediatric units and for that reason paediatric nursing students have to possess good mathematical skills (Doherty C, 2012). It is important to evaluate these competences during their university nursing degree (Harvey 2009). This problem has been discussed and it was subsequently decided to introduce 'Clinical and Practical pharmacology' lessons like a mandatory subject.

Aim: Evaluate the paediatric nursing students learning curve before and after 'Clinical and Practical pharmacology' lessons, job placement and through an e-learning platform.

Methods: A before and after experimental study, using a non-randomized test, administered at different academic phases was used.

Results: Learning curve had an increase from $54.09 \%$ to $82.65 \%$. In particular, that result is significant before 'Clinical and Practical pharmacology' lessons and at final test $(\mathrm{p}<0.00578)$.

Conclusion: These study results are helpful for increased training action and to develop a customized e-learning platform.

\section{OC17 - Merging the person and the illness: the lived experience of emerging adults with childhood onset chronic illness}

Siobhan Macdermott (Ireland) ${ }^{1}$; Pamela Hussey (Ireland) ${ }^{1}$

${ }^{1}$ Dublin City University

Theme: Transition of care.

Keywords: Childhood onset chronic illness, illness narratives, phenomenology.

Chronic illness is emerging as major health problem in the developed world. This study explored the lived experiences of emerging adults who have lived with chronic illness since childhood in Ireland. Emerging adults often fare worse than adolescents in many areas, including adherence to treatment, and are more likely to have social, emotional and behavioural problems than their healthy counterparts. A phenomenological approach 
provided the methodology for studying of the lived experience of 15 participants aged 18 and 25 years living in Ireland who had a self-reported chronic illness since childhood. Drawing on the philosophy of van Manen's lifeworld existentials, the lived experiences were revealed. Emerging adults struggle to achieve a sense of identity which is often sabotaged by illness. The findings of this study conclude that a sense of connectedness with peers was important for emerging adults with illness as they journeyed towards developing a sense of identity.

\section{OC18 - Neurodevelopmental outcomes following congenital heart surgery}

Eleni Syrgani (Greece) $)^{1,2}$; Konstantinos Petsios (Greece) $)^{1,2}$

${ }^{1}$ National Kapodistrian University of Athens; ${ }^{2}$ 'Onassis' Cardiac Center-PICU

Theme: Complex health care and chronic disease management.

Keywords: Congenital heart disease, developmental disabilities, outcome, neurodevelopment delay.

Introduction: Congenital heart disease (CHD) may have a very important impact on central nervous system function and neurodevelopment.

Purpose: Critical evaluation of literature concerning the neurodevelopmental outcomes following congenital heart surgery.

Methods: Systematic review of 28 articles published after 2000 in PubMed, Scopus and CINAHL.

Results: Neurodevelopment morbidities can have a negative impact on early childhood development, academic performance and later transition to adulthood. The spectrum of neurodevelopment impairment is wide, depending on the complexity of $\mathrm{CHD}$ and it is characterized by mild cognitive impairment, impaired social interaction, and impairments in core communication skills, including pragmatic language, as well as inattention, impulsive behavior and impaired executive function. A number of important determinants are presented.

Conclusions: Children with CHD are at increased risk for neurodevelopmental delay. Screening and evaluation of neurodevelopmental delay, along with regular follow up, are essential steps to guide appropriate interventions to optimize their overall development.

\section{OC19 - Measuring feasibility, reliability and validity of the Greek version of PedsQL cardiac module}

Maria Drakouli (Greece) ${ }^{1,2}$; Konstantinos Petsios (Greece) ${ }^{1,2}$;

Vasiliki Matziou (Greece) ${ }^{1}$

${ }^{1}$ National and Kapodistrian University of Athens; ${ }^{2}$ Onassis Cardiac Center-PICU 
Theme: Cardiology

Keywords: Adolescents, children, quality of life, PedsQL Cardiac Module, validation.

Introduction: Measuring quality of life (QoL) in children and adolescents with congenital heart disease $(\mathrm{CHD})$ is of great clinical importance.

Objective: The aim of the study was: (a) to adapt the PedsQL Cardiac Module for children aged two to 18 years with $\mathrm{CHD}$ in a sample of the Greek population; (b) to determine its reliability and validity.

Methods: Forward and backward translation methodology was used. Parents and children completed the instrument during: (a) hospitalization and (b) visits in the paediatric cardiology outpatient department. Cross-informant variance between children and parents was thoroughly assessed.

Results: Missing item responses did not exceed 5\%. All internal consistency reliability coefficients for the inventory exceeded the minimum standards for group comparisons, over 0.75 . Hypothesized correlations between cardiac module and core scales were statistically significant, $(p<0.05)$. Agreement between children and parents was relatively high. Pilot study results will be additionally presented.

Conclusion: The findings support the feasibility, reliability and validity of the Greek translation of the PedsQL Cardiac Module in children with congenital heart defect (CHD).

\title{
OC20 - Skin-to-skin contact in the first hour of life
}

\author{
Manuela Ferreira (Portugal)i; Tânia Vaz (Portugal)2; \\ Graça Aparício (Portugal)ํㅜ; João Duarte (Portugal) ${ }^{1}$
}

\section{${ }^{1}$ Instituto Politécnico de Viseu - Escola Superior de Saúde CI\&DETS; ${ }^{2}$ Centro Hospitalar Cova da Beira}

Theme: Child protection and managing risk.

Keywords: Breastfeeding, newborn, skin-to-skin contact.

Background: Skin-to-skin contact in the first hour of life has benefits for the mother and the newborn, as well as a major role in establishing breastfeeding.

Objectives: Determine the prevalence of skin-to-skin contact and breastfeeding within the first hour of life.

Method: A systematic review of literature followed by a quantitative and simple descriptive cross-sectional study, according to a non-probability analyzing of 382 clinic records of postpartum mothers.

Results: Evidence that early skin-to-skin contact immediately after birth is a potential sensory stimulus, which covers the newborn warming, tactile and active stimulation, respiratory rates and level of blood glucose, reduces baby crying and promotes breastfeeding. In the sample, about $92.6 \%$ of the mothers put the baby to the breast in the first hour of life, but only $26.6 \%$ made skin-to-skin contact with the baby.

Conclusion: Despite the scientific evidence of the benefits of skin-to-skin contact 


\title{
OC21 - Psychosocial functioning of parents of infants diagnosed with complex congenital heart defect
}

 \\ Ioanna Voutoufianaki (Greece) ${ }^{1}$; Anna Manatou (Greece)ㄹ; \\ Prodromos Azariadis (Greece) ${ }^{1}$; Spiros Rammos (Greece) ${ }^{1}$ \\ ${ }^{1}$ 'Onassis' Cardiac Center; ${ }^{2}$ - Faculty of Nursing, National and Kapodistrian \\ University of Athens
}

Theme: Parenting/parenthood.

Keywords: Congenital heart defect (CHD), parenting, psychosocial.

Introduction: The diagnosis of complex CHD impacts the psychosocial status of parents and their functioning.

Purpose: A critical evaluation of the literature concerning the psychosocial parental response to their infant's diagnosis of complex CHD.

Methods: Systematic review of 18 articles published after 2000 in PubMed and CINAHL.

Results: The impact of an infant's CHD on the family functioning is determined both by child's medical condition and family's psychosocial factors. The majority of parents experience intense loss and numerous stressors. Nurses and physicians need to be sensitive to the needs, thoughts and experiences of the parents when discussing treatment options. Families with poor social support networks may have the greatest need for professional interventions.

Conclusions: Appropriate interventions assist the majority of parents to adapt to the diagnosis of complex CHD. However, there are a number of parents with an increased psychosocial risk associated with higher rates of emotional distress.

\section{OC22 - Light House Project}

Gonçalo Pereira (Portugal)i; Ana Baridó (Portugal)²

${ }^{1}$ Universidade Católica Portuguesa - Instituto de Ciências da Saúde - Lisboa;
${ }^{2}$ ACES Leiria

Theme: Accreditation and quality improvement.

Keywords: Adolescents, indicators, nursing care, nursing consultation, quality improvement.

In the context of primary health care internship of a master's degree in paediatric nursing ministered by 'Universidade Católica Portuguesa' in Lisbon, and after diagnosing a 
community issue, was proposed the creation of an adolescents nursing consultation. This idea gave birth to the 'Light House Project'.

Four areas of focus were explored and objectives outlined. The general objective was to promote the community adolescent's health in matters of mental health, sexuality, interpersonal relationships and healthy lifestyle, with each of the areas having its own objectives. The purpose was being able to demonstrate, quantify and evaluate the fulfilment of the objectives. Instruments or indicators of structure, process and result were created. Those instruments were built according to instructions made available by the 'Ordem dos Enfermeiros' in Nursing Care Continuous Quality Improvement Project Organization Script and also according to International Classification for Nursing Practice. As result of this work, and during the first half of 2016, a new service was to be opened specifically for adolescents, comprising a multidisciplinary team, with a nursing consultation and dedicated instruments that will allow the continuous improvement of the nursing care provided by this service.

\title{
OC23 - Expert mentoring: a path to leadership
}

\author{
Carol Hall (United Kingdom) ${ }^{1}$; Paula Dawson (United Kingdom)i; \\ Laura Holliday (United Kingdom)1
}

\section{${ }^{1}$ University of Nottingham School of Health Sciences}

Theme: Nursing education, management and leadership.

Keywords: Contemporary nursing challenge, expert mentor, leadership, problem-solving, teamwork.

Leadership knowledge and skills development may be understood in terms of problem-solving, solution construction and social judgement needed to solve organizational problems (Mumford, Zaccaro et al 2000). Capacity and courage to lead as a nurse for children and young people will impact upon all elements of health care, from direct care to service commissioning (RCN 2014).

Final year undergraduate MSc child nursing students worked in action learning sets, facilitated by nationally recognised expert mentors, and were required to identify, explore and tackle a contemporary challenge in nursing practice, considering strategic, managerial and operational issues.

Student groups presented their findings, analyses, recommendations and reflections upon team and individual development at a shared conference event.

Our presentation will discuss perceived immediate and longer-term effects of participation in this innovative educational initiative of current students and alumni on career aspirations and trajectories, networking skills, knowledge and confidence to lead and challenge in professional practice. 


\title{
OC24 - An algorithm proposal to oral feeding in premature infants
}

\author{
Florbela Neto (Portugal) ${ }^{1}$; Ana Paula França (Portugal)2; \\ Sandra Cruz (Portugal) $)^{2}$
}

${ }^{1}$ ICBAS-Instituto de Ciencias Biomédicas Abel Salazar; ${ }^{2}$ ESEP-Escola Superior de Enfermagem do Porto

Theme: Transition of care.

Keywords: nursing interventions, premature feeding skills, sucking, swallowing.

Introduction: Oral feeding is one of the hardest steps for premature infants after respiratory independence and is a challenge for nurses in neonatology.

Objectives: To know the characteristics of preterm infants, essential for oral feeding; to know the nurses' opinion on nursing interventions, that promote the transition of gavage feeding for oral feeding in preterm infants.

Methods: An exploratory, descriptive study with a qualitative approach was used.

Semi-structured interviews with neonatal nurses were conducted and data was submitted to content analysis.

Results: Weight, gestational age, physiological stability, sucking coordination, swallowing and breathing, and the overall look and feeding involvement are fundamental parameters to begin oral feeding. Positioning the baby, reflexes stimulation, control stress levels, monitoring the temperature and the milk flow are nursing interventions that promote the development of feeding skills.

Conclusion: An algorithm for the oral feeding of preterm infants was developed grounded in the opinions of nurses.

\section{OC25 - Helping parents spot the deteriorating child: co-production of safety-netting interventions}

Sarah Neill (United Kingdom) ${ }^{1 ;}$, Damian Roland (United Kingdom)2;

Matthew Thompson (United States of America);

Juliet Usher-Smith (United Kingdom) ${ }^{4}$; Laura Mullins

(United Kingdom); ; Monica Lakhanpaul (United Kingdom) ${ }^{6}$

${ }^{1}$ University of Northampton; ${ }^{2}$ University of Leicester and Univeristy Hospitals Leicester; ${ }^{3}$ University of Washington; ${ }^{4}$ University of Cambridge; ${ }^{5}$ Lay member;

${ }^{6}$ University College London

Theme: Child protection and managing risk.

Keywords: Acute illness, co-production, patient safety, safety netting. 
Introduction: Providing families with a safety net of information is a crucial component in the care of children with acute illnesses at home (Jones et al 2013). Safety netting is recommended by UK national bodies and has been found to reduce re-consultation safely (Maguire et al 2011).

Aim: To provide parents with information to help them determine when to seek help for an acutely ill child.

Methods: Research programme encompassed five projects: a systematic review; a qualitative exploration of safety netting information used by parents and professionals; a mixed methods development of content, format and delivery modes for the first intervention; video capture of children with acute illness; and co-design of the content of the intervention with parents and professionals.

Conclusion: ASK SNIFF projects repeatedly demonstrate the need for professionally endorsed, co-produced safety-netting resources for parents with varying information needs, literacy levels and ability to use information technology.

\title{
OC26 - Parents of young children in research: informants, consultants and collaborators
}

\author{
Sarah Neill (United Kingdom) ${ }^{1}$; Damian Roland (United Kingdom)2; \\ Matthew Thompson (United States of America); ${ }^{3}$ Natasha Bayes \\ (United Kingdom) $)^{1}$; Laura Mullins (United Kingdom) ${ }^{4}$; \\ Monica Lakhanpaul (United Kingdom) ${ }^{5}$
}

${ }^{1}$ University of Northampton; ${ }^{2}$ University of Leicester and University Hospitals Leicester; ${ }^{3}$ University of Washington; ${ }^{4}$ Lay member; ${ }^{5}$ University College London

Theme: Ethical issues: dignity and humanity.

Keywords: Parents, research participation; research involvement; research collaboration.

Introduction: Patient and public involvement in research is recognised as best practice in the UK, as services developed with service users are more likely to meet their needs. In child health this often means engaging with parents of young children.

Aim: To share experiences of engaging with parents of young children in research projects at varying levels of participation.

Methods: Methods include parents as participants, as parent panels and as research team members reflecting various steps on the participation ladder (Hart 1992).

Results: Parents report personal benefits and a range of different challenges when engaging in child health research which impact the management/delivery of research projects.

Conclusion: Key elements of working with parents include time to plan involvement, building respect/mutual understanding, equal access to project activities, continual support for parents, reward and recognition. Research projects need to cost and plan for parents' engagement in research for it to be successful. 


\title{
OC27 - How to manage teenagers' emotions? Proposal of an algorithm for nursing intervention
}

\author{
Maria João Caeiro (Portugal)1,2; Paula Diogo (Portugal) ${ }^{1,3}$ \\ ${ }^{1}$ UI\&DE: Research Line 'Emotions in Health'; ${ }^{2}$ CHLC-Hospital D. Estefânia, Unidade \\ de Adolescentes; ${ }^{3}$ Escola Superior de Enfermagem de Lisboa, ESEL
}

Theme: Complex health care and chronic disease management.

Keywords: Emotional labour, hospitalization, paediatric nursing, teenagers.

The singular human experience of emotions is a relevant subject of nursing care. It determines not only the importance of emotions, but also the underlying knowledge required in nursing practice.

The algorithm aims at giving a directed answer according to clients' emotional responses, while mitigating or minimizing emotionally intense situations. Since such situations are disturbing and add suffering to the illness and hospitalization experience, one of the main purposes of nursing is alleviating the client's emotional suffering - the emotional labour. This algorithm was applied in three paediatric services where its importance emerged. We intend to develop an action research project to validate and apply the algorithm in a specific context.

As a new, singular approach, it will allow the individualization, guidance and adjustment of nursing care in an intentional way, addressed to a specific population; hence we believe that this will be a useful tool for teenagers' nursing care.

\section{OC28 - Effect of mode of delivery on early oral colonization and childhood dental caries: a systematic review}

Celeste Antão (Portugal)2 ${ }^{2}$ Cristina Teixeira (Portugal)1;

Maria José Gomes (Portugal)²

${ }^{1}$ EPI Unit, Public Health Institute, University of Porto, Portugal; ${ }^{2}$ Núcleo de Investigação e Intervenção do Idoso, Polythecnic Institute of Bragança, Bragança, Portugal

Theme: Multidisciplinary team working.

Keywords: Early childhood caries, early oral colonization, acquisition of oral microflora, mode of delivery.

Background: Oral colonization starts at birth by vertical transmission.

Objective: To determine whether mode of delivery influences the oral colonization of infants and contributes to the risk of childhood dental caries.

Methods: A systematic review was conducted in the electronic database Web of Science for articles published from January 1995 to December 2015 by using a set of keywords. 
Results: From 2,644 citations identified through electronic search, ten studies met the inclusion criteria. According to the studies mode of delivery influences oral microbial density, oral microbial profile and the timing of oral colonization by cariogenic microbiota. However, there are no consistent results concerning either the prevalence of children harboring cariogenic microbiota or the prevalence of early childhood caries by mode of delivery.

Conclusion: Mode of delivery influences early oral colonization. However, it seems that other determinants rather than mode of delivery could be major contributors to the development of early childhood caries.

\title{
OC29 - Caregiver burden in childhood asthma
}

\author{
Ayfer Ekim (Turkey) ${ }^{1}$ \\ ${ }^{1}$ Istanbul Bilgi University School of Health Sciences Department of Nursing
}

Theme: Parenting/parenthood.

Keywords: Burden, caregiver, childhood asthma, parent.

Introduction: As delivering care is an inherent part of becoming parents, providing highlevel care to the child with health problems might be a burden for the caregiver.

\begin{abstract}
Aim: This systematic review investigated the effects of caregiver burden of parents who are primarily responsible for the caring of children with asthma.
\end{abstract}

Methods: PubMed, CINAHL, Web of Science and Scopus databases were searched for the studies published between 2000-2015. Key search terms used were 'caregiver', 'burden, 'childhood asthma' and 'parent'.

Results: A total of 23 studies were examined for this review.

Discussion: Providing care to the child with asthma affects parents as caregivers negatively. Caregivers of the children with asthma often experience anxiety, fear, disappointment, grief, physical distress and low quality of life as the outcomes of caregiving burden.

Conclusions: It is absolutely crucial to determine caregiver burden risks and protective factors since wellness level of caregivers affect the asthma management practices and decisions.

\section{OC30 - Fracture reduction with nitrous oxide at the children's emergency department shortens the length of stay and reduces the use of full anaesthesia in the operating department}

Sigrid Lang (Sweden)ㄹ; Anna-Pia Wentzel (Sweden)루

Malin Ekstrom (Sweden) ${ }^{1}$

${ }^{1}$ Queen Silvias Hospital, Gothenburg

Theme: Accreditation and quality improvement. 
Keywords: Nitrous oxide, length of stay, fracture reduction.

Aim: Dislocated fractures are common in the children's emergency department (ER). All forms of fracture reduction are very painful requiring nitrous oxide. The purpose is to shorten the length of stay in the hospital as well as sustain a high quality of care.

Methods: All nurses received theoretical and practical training in the use of nitrous oxide. Evaluations with the families were made by telephone.

Result: A total of 40 enclosed fracture reductions were made at the ER, leading to a reduction of 33 patients in the operating department and the length of stay was shortened this compared to the same time in 2014.

No adverse event was reported and no patient felt any increase in pain during the treatment. All patients would repeat the procedure if necessary.

Conclusion: The treatment has reduced the length of stay in the hospital without affecting the other patients in the ER or the quality of care.

\title{
OC31 - Tobacco consumption by adolescents: a study in the north of Portgual
}

\author{
Margarida Reis Santos (Portugal) ${ }^{1}$; Sandra Cruz (Portugal) ${ }^{1}$; \\ Susana Fernandes (Portugal)2
}

${ }^{1}$ ESEP; ${ }^{2}$ ULSNE - UCC Mogadouro

Theme: School health.

Keywords: Adolescents, risk behaviours, tobacco.

Aims: To characterize the adolescents' habits of smoking in a Portuguese School; to identify if the adolescents have information on the harmful effects of tobacco and their health education needs.

Methods: Quantitative, exploratory and descriptive study. Data collection in 2011 through a self-answered questionnaire.

Results: The sample comprised 441 students; mean age of 14.5 years old; $53.1 \%$ were male; $18,6 \%$ were smokers; boys smoked more than girls; they started to smoke between 7-18; the tobacco consumption is significantly related with: age $(p<0,001)$; gender $(p=0,002)$; interest of the family about the adolescents' problems $(p=0,028)$ among others. The adolescents have information about the harmful effects of tobacco and the ones interested in receiving more information wanted it from the health professionals.

Conclusions: Prevention and delaying the age of initiation of consumption should be taken into account in a target intervention plan, which should be led by the school health nurse. 


\title{
OC32 - Nursing interventions for empowering parents of premature infants before discharge from the neonatal intensive care unit: a scoping review
}

\author{
Denise Araújo (Portugal) ${ }^{1}$; Maria do Céu Barbieri-Figueiredo \\ $(\text { Portugal })^{2}$
}

${ }^{1}$ ICBAS, Universidade do Porto; ${ }^{2}$ Escola Superior de Enfermagem do Porto

Theme: Complex health care and chronic disease management.

Keywords: Discharge, family, nursing, premature infant, transitional care, nursing.

Family-centred nursing interventions in perinatal period are of utmost importance for empowering parents and preparing the discharge from neonatal intensive care unit. The purpose of this scoping review was to summarize the available evidence related to familycentred nursing interventions during hospitalization in perinatal period, of infants born with less than 37 weeks of gestational age, for empowering parents before discharge from hospital.

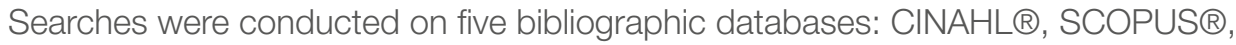
MEDLINE®, MEDLACTINA®, Cochrane Central Register of Controlled Trials $®$. A total of 15 studies, published between 2004 and 2015, were included in the review. Nurses considered the following issues as essential for discharge preparation and empowerment of families: availability of social aids for vulnerable families, 24-hour telephone access to the neonatal units, tailored educational materials and group sessions, continuing education for staff and community-based support to parents post-discharge.

\section{OC33 - Young people's eating behaviours in Vila Nova de Famalicão}

\author{
Ilda Fernandes (Portugal) ${ }^{1}$; Manuela Martins (Portugal) ${ }^{1}$; \\ Luísa Andrade (Portugal) ${ }^{1}$; Sara Soares (Portugal) ${ }^{1}$
}

${ }^{1}$ ESEP

Theme: Nutrition

Keywords: Adolescent, eating, health behaviours, social determinants.

Overweight and obesity are prevalent health problems among young people, with implications on wellbeing and health in adult life. A quantitative, descriptive and transversal study was performed to analyse the eating behaviours perception of adolescents from a school community in Vila Nova de Famalicão. A self-administered questionnaire was applied to 1,614 adolescents attending secondary and higher education in the academic year 2013/14, aged between 14-21 years.

From the total participants, 56.9\% were female and 86.5\% attended secondary school. Results showed that $85.3 \%$ ate a variety of food, including animal origin products; $32.1 \%$ 


\title{
OC34 - Paediatric rehabilitation: humanizing nursing care to children and their families
}

\author{
Ana Paula Marques França (Portugal)룰 Alda Rosa Barbosa \\ Mendes (Portugal) ${ }^{1}$; Mariana Inês Fernandes Barrias (Portugal) ${ }^{2}$ \\ ${ }^{1}$ Escola Superior de Enfermagem do Porto - Nursing School of Porto; ${ }^{2}$ Centro de \\ Reabilitação do Norte
}

Theme: Ethical issues - dignity and humanity.

Keywords: Ethics, humanization, nursing care, paediatric rehabilitation, paediatric nursing.

Introduction: The child with special health care needs in a rehabilitation center for their vulnerable condition requires a clinical practice centered on ethics and humanization.

Objectives: To know the parents' and nurses opinions on humanized care in a paediatric rehabilitation unit and to identify needs and strategies that promote the humanization of care in a paediatric rehabilitation unit.

Methods: Qualitative, descriptive, exploratory study, using interviews with nurses and questionnaires to parents of hospitalized children.

\begin{abstract}
Results: This study enhances the importance that nurses should have in human relationships, with special attention to each child and their parents, but also to the structural and functioning conditions of the unit.
\end{abstract}

Discussion: The results are in agreement with the literature, highlighting the particular aspects of children with special needs and their parents.

Conclusion: The results contribute to more humanized care and could be a basis for a Charter of Humanization.

\section{OC35 - Child Friendly Healthcare Initiative, implementation project in a paediatric department in Greece}

Barbara Boutopoulou (Greece) ${ }^{1}$; Andrew Clarke (United

Kingdom) ${ }^{2}$; Ioanna Christothanopoulou (Greece)';

Konstantinos Douros (Greece) ${ }^{1}$; Maria Tsirouda (Greece) ${ }^{1}$;

Vasiliki Papaevangelou (Greece) ${ }^{3}$

${ }^{1}$ 3rd Dept of Paediatrics, 'Attikon' Hospital; ${ }^{2}$ Public Health Development Lead (Children \& Families) - Lancashire Care NHS Trust; ${ }^{3} 3 r d$ Dpt of Paediatrics, National and Kapodistrian University of Athens School of Medicine, 'Attikon' Hospital 
Theme: Accreditation and quality improvement.

Keywords: Child friendly, quality of care.

Introduction: Child Friendly Healthcare Initiative (CFHI) aims to improve quality of experience and health care given to children and families by improving realisation of children's rights and reducing unnecessary fear, anxiety and suffering during and because of health care.

Aim: To present results of preliminary CFH assessment.

Methods: Implementation was initiated in a paediatric department of a University Hospital in Athens, Greece, consisting of a 37-bed ward, Outpatient Clinic and Emergency Department. For the preliminary assessment of the $\mathrm{CFHI}$ tool No1, which is for parents-caregiverschildren and health workers, this was translated into Greek. 112 parents-caregivers and six children were interviewed by an independent interviewer. In total, 24 health workers -5 paediatricians, 11 residents and 8 nurses - responded to the CFHI tool No 1.

Results: Issues highlighted were mostly about CFH Standard 3 and Standard 7. Suggestions for improvement in all Standards were suggested.

Conclusions: Preliminary assessment revealed the quality of care needs improvement. The next step is the training health workers, planning and making improvements.

\title{
OC36 - Diagnostic approach of primary cilia dyskinesia: Greek experience
}

\author{
Barbara Boutopoulou (Greece) ${ }^{1}$; Marios Papadopoulos (Greece); \\ Konstantinos Douros (Greece) $)^{1}$; Iordanis Papadopoulos (Greece)ㄹ; \\ Basilis Grammeniatis (Greece) ${ }^{1}$; Kostas Priftis (Greece) ${ }^{1}$
}

\section{${ }^{1}$ 3rd Dept of Paediatrics, 'Attikon' Hospital}

Theme: Complex health care and chronic disease management.

Keywords: Diagnostic approach, primary cilia dyskinesia.

Introduction: Primary Cilia Dyskinesia (PCD) is a rare, genetically heterogeneous disease that causes chronic pulmonary inflammation and progressive loss of lung function due to the dysfunction of cilia.

Aim: To present the Greek experience in development and implementation of standardized operational procedures (SOP) in diagnostic testing of PCD.

Methods: After special training, SOP consisting of nasal $\mathrm{NO}(\mathrm{nNO})$ measurement, high speed videomicroscopy (HVM), transmission electron microscopy (TEM) and shipment of the sample for high resolution immunofluorescence (IF) microscopy in difficult cases, were applied.

Results: From September 2014 until December 2015197 tests were performed to 147 suspected patients. 17 patients were finally diagnosed with PCD.

Conclusions: PCD is a rare disease that can be diagnosed through SOP. Early diagnosis and appropriate treatment of PCD will reduce not only the morbidity and mortality to 
patients, but also the burden of healthcare costs.

\title{
OC37 - Adolescents with cystic fibrosis: their perspective
}

\author{
Maria Conceição Reisinho (Portugal)ª́r Bárbara Gomes (Portugal) \\ 1 - Escola Superior de Enfermagem do Porto
}

Theme: Complex health care and chronic disease management.

Keywords: Adolescent, cystic fibrosis, transitions.

Introduction: The adolescent with cystic fibrosis suffers from organic distresses and requires support to deal with the physical symptoms and the psychosocial adaptation.

Aim: Realize the experience of growing up with cystic fibrosis from the adolescent point of view.

Methodology: Data grounded theory as investigation method and interpretation by Meleis Theory. Study group with 16 adolescents and data collected by interview.

Results: From the content analysis of the interviews, we established that the adolescents were living development and health-illness type transitions. We identified the dimension 'developing trust and coping' as adjustment strategy to new contexts.

Discussion: The adolescents' speeches reflected behaviors of involvement in the transition process, being a positive result to the psychosocial development and positive life experience at this stage.

Conclusion: The follow up from healthcare professionals may transform a stressful situation into a state of trust. It can also reveal and pinpoint resource strategies to enable adaptation to new circumstances.

\section{OC38 - Beyond boundaries: inter-professional simulation in children and young people's nursing - three pilot projects}

Dave Clarke (United Kingdom) ${ }^{1}$

${ }^{1}$ Cardiff University

Theme: Nursing education, management and leadership.

Keywords: Inter-professional, medical students, occupational therapy students, simulation. Inter-professional collaboration is essential for safe, high-quality, patient-centered care (Shanahan and Lewis 2015). In order to set the stage for inter-professional collaboration, inter-professional education should be incorporated into the learning experience of health professionals (Reese et al 2010).

In this presentation I will share the development of two undergraduate inter-professional education pilot projects and the evaluations from these. This comprised of two projects: 
children's nursing students and occupational therapy students, and children's nursing students and fourth-year medical students. Each had a different focus: the first is based upon assessment of a child in a community simulation, whilst the second focused on the inter-professional assessment of the acutely ill child.

I will present the results of these two successful inter-professional simulation innovations and then discuss the future of inter-professional education. I will conclude by presenting our current project which is a practice-based inter-professional education intervention involving up to eight professional groups.

\title{
OC39 - The efficacy of a participatory approach in reducing pain related to venepuncture in children
}

\author{
Andrea Gazzelloni (Italy)'; Mariagrazia Maio (Italy)2 ; \\ Maria Romano (Italy) ${ }^{2}$; Iolanda Marcone (Italy) ${ }^{2}$; Franca Marino \\ $(\text { Italy })^{2}$; Monia Cosima Labalestra (Italy) ${ }^{2}$
}

${ }^{1}$ Bambino Gesù Children's Hospital; ${ }^{2}$ 'San Carlo' Hospital - Potenza

Theme: Ethical issues: dignity and humanity.

Keywords: Children, ice, illustration, pain, venepuncture.

Introduction: Venepuncture represents traumatic experience in childhood due to pain and discomfort.

Aims: To compare the efficacy of a participatory approach with preliminary ice application to the skin.

Methods: Two age-groups (respectively 3-7 and $\geq 8$ years) were considered during dayhospital, hospitalization, and ER accesses. Venepuncture was described to patients with fables or illustration according to the age-group. Ice or cool-water-pack was randomly applied to skin for one minute before venepuncture. Pain measurement scales were Wong-Baker and VAS.

Results: Preliminary data (55 patients) showed that the 3-7 years age group had better pain tolerance with a participatory approach, whilst ice was better in the older group. Generally previous venepunctures seem to worsen pain feeling.

Discussion: Imagination seems to influence pain feeling in the 3-7 age group, while ice is more important in the older group. Previous experiences mark negatively successive venepunctures.

Conclusions: Participatory approaches can be cost-effective and influences positively venepuncture in the future. 


\title{
OC40 - Family participation in caring for hospitalized children - nurses' perspectives
}

\author{
Margarida Reis Santos (Portugal); Natália Quina Lopes \\ $(\text { Portugal })^{2}$; Paula Sousa (Portugal) ${ }^{1}$ \\ ${ }^{1}$ ESEP; ${ }^{2} H S J$
}

Theme: Professional issues

Keywords: Hospitalized child, negotiation, paediatric nurse, partnership care.

Aim: To understand nurses' perspective about the presence and participation of parents/ caregivers during child's hospitalization.

Method: Quantitative, descriptive and exploratory study. Data collection in 2011 through questionnaire.

Results: The sample comprised 146 nurses that work in paediatric wards in five different hospitals in the North of Portugal; aged between 23 to 59 years old; 93.1\% were female; the average professional time was 10.7 years with 9.4 years of professional practice in an inpatient paediatric ward; 89\% recognize the importance of parents/caregivers staying at hospital all day with their children during hospitalization; 63.4\% always promote the involvement of parents/caregivers in the basic care; $42.5 \%$ involved them in more complex care; $9.6 \%$ didn't have the habit of explaining the nursing care to the parents before performing them.

Conclusions: It is important that nurses recognize the benefits of effectively involving parents/caregivers in the care, negotiation and decision-making process regarding the child's care.

\section{OC41 - Families of children with Down syndrome: a cross-cultural study}

\author{
Marcia Van Riper (United States of America)1; George Knafl \\ (United States of America) ${ }^{1}$; Elysangela Dittz Duarte (Brazil) ${ }^{2}$; \\ Hyunkyung Choi (Korea, South) $)^{3}$
}

${ }^{1}$ University of North Carolina at Chapel Hill; ${ }^{2}$ Escola de Enfermagem, Universidade Federal de Minas Gerais; ${ }^{3}$ Kyungpook National University College of Nursing

Theme: Cross-cultural nursing.

Keywords: Adaptation, Down syndrome, family, family factors, resiliency.

The birth of a child with Down syndrome (DS) is a life-changing event for families. However, many families adapt successfully and some even thrive. The purpose of this cross-cultural study was to identify family factors associated with family functioning in three age-based groups of families. 1,107 parents from 6 countries completed an online survey guided by the Resiliency Model of Family Stress, Adjustment and Adaptation. For all three groups, family functioning was better with greater affirmative communication and greater hardiness, 
and worse with greater incendiary communication. Other family factors having a significant influence for at least one group were mutuality, family strains, and condition management ability. Findings contribute to our understanding of the underlying processes associated with age-based differences in family functioning in families of children with DS. Nurses need to recognize the importance of family factors and understand that different family factors may gain importance as the child ages.

\title{
OC42 - What do parents know about fever?
}

\author{
Manuela Pereira (Portugal) ${ }^{1}$; Isabel Bica (Portugal)2; João Duarte \\ (Portugal)2; Margarida Reis Santos (Portugal)³; Ernestina Silva \\ (Portugal) ${ }^{2} ;$ Patrícia Costa (Portugal) ${ }^{4}$
}

${ }^{1}$ ACES Dão Lafões - USF Alves Martins, Viseu; ${ }^{2}$ CI\&DETS - Health School of Viseu
- Polytechnic Institute of Viseu; ${ }^{3}$ Escola Superior de Enfermagem do Porto; ${ }^{4}$ ACeS
Dão Lafões, USF Terras de Azurara, Mangualde

Theme: Parenting/parenthood.

Keywords: Children, fever, knowledge, parents.

Introduction: Due to lack of information, the fever in the child brings anxiety and fear to their parents.

Objectives: To identify parents' knowledge towards the child with fever and the sources of information they have used.

Methods: Cross-sectional, descriptive-correlational study. Convenience not probabilistic sample of 360 parents with children in child health surveillance consultation, in central Portugal. Data collection was performed by a questionnaire about fever in children.

Results: Knowledge of the fever was found to be weak among parents aged $\geq 38$ years (36.2\%) with a partner (77.0\%), living in rural areas (69.3\%) and having completed the ninth grade (53.9\%). Parents up to 37 years (68.2\%) with a partner (89.0\%), living in urban area (53.0\%) and having higher education (43.3\%) showed good knowledge. The main sources of information were the doctor (65.8\%) and nurses (50.6\%).

Conclusion: Nurses need to invest in training parents more on this subject.

\section{OC43 - Reproductive decision-making in families of children with Down syndrome}

\author{
Marcia Van Riper (United States of America) ${ }^{1}$ \\ ${ }^{1}$ University of North Carolina at Chapel Hill
}

Theme: Ethical issues: dignity and humanity.

Keywords: Down syndrome, prenatal, ethical issues, genetic testing, family.

Reproductive decision-making generally becomes much more complex in families once they have given birth to a child with a genetic condition. The question of whether or not to have 
additional children often takes on new meaning, as does the decision to undergo prenatal testing. The purpose of this presentation is to explore reproductive decision-making in families who already have one child with Down syndrome (DS). Five stories from an ongoing cross-cultural study about adaptation and resilience in families of children with DS will be presented. The stories to be presented were purposefully selected because they vividly illustrate the complexity of reproductive decision-making in these families. Moreover, they show that for many families, the prenatal testing experience can be a stressful experience filled with ethical issues. Currently, there is an urgent need for more dialogue between families of children with DS and their health care providers concerning reproductive decision-making.

\section{OC44 - Supporting the behavioural health of children: temperament-based interventions to support development and reduce risk}

Pamela Galehouse (US) ${ }^{1}$

\section{${ }^{1}$ Seton Hall University}

Theme: School health.

Keywords: Assessment, environmental modifications, temperament.

Temperament has been described as a composite of innate characteristics best reflected in an individual's immediate response to change in his or her environment. Responses are automatic and not effected by context, ability or motivation. Some profiles of temperament present risk to developing self-control, both behavioral and emotional.

Today, nurses encounter large groups of children exposed to chaotic environments that threaten their immediate health, as well as their ability to transition into new environments and to integrate into the school and community environment. Understanding a child's unique temperament provides a framework for understanding his or her behavior and responding in a way that promotes self-understanding and behavior modification. Several successful school-based intervention programs will be identified.

In this presentation an assessment of child temperament will be reviewed, two 'challenging' temperament profiles that pose increased risk will be identified and strategies for responding to behavior in the school will be described.

\section{OC45 - Towards family-centred care in neonatal intensive care unit}

Maria Do Céu Barbieri-Figueiredol; Madalena Ramos (Portugal)2;

Branca Oliveira (Portugal) 2; Eugénia Fernandes (Portugal)2;

Florbela Neto (Portugal) ${ }^{2}$

${ }^{1}$ Escola Superior de Enfermagem do Porto; ${ }^{2}$ Centro Hospitalar de S. João, Hospital Pediátrico Integrado

Theme: Complex health care and chronic disease management. 
Keywords: Family-centred care; Neonatal Intensive Care Unit, neonatal nursing.

Family-centred care is a philosophy of care characterized by partnership and respect between healthcare professionals and families (and patients), demanding a systematic assessment of the complexity of each family, including their beliefs and values, communication style, and ability to make decisions.

This presentation will unfold the evolution of nursing care delivered at a Neonatal Intensive Care Unit of a University Hospital in the north of Portugal, since its origin in 1983 to the present day.

Some milestones will be analysed such as the inclusion of parents in the care delivery, the implementation of kangaroo care, the systematic discharge protocol or the recent award of Newborn Individualized Developmental Care and Assessment Program (NIDCAP) Certified Centre.

Next developments, starting this year, include the development of the primary nursing model for nursing staff allocation and quality audits for assessing quality of care and patient safety.

\title{
OC46 - NIDCAP at hospital São João - the journey
}

\author{
Madalena Ramos (Portugal)'; Carla Castro (Portugal)'; \\ Florbela Neto (Portugal) $)^{1}$; Ligia Silva (Portugal) \\ Fátima Clemente (Portugal) ${ }^{11}$; Hercília Guimarães (Portugal) ${ }^{1}$
}

${ }^{1}$ Centro Hospitalar de São João, Hospital Integrado de Pediatria

Theme: Complex health care and chronic disease management.

Keywords: Newborn Individualized Developmental Care and Assessment Program (NIDCAP), Neonatal Intensive Care Unit (NICU), premature.

In 2003, a group of professionals from Oporto went to Boston in the United States in order to get to know the NIDCAP program and brought it to Portugal, because they believed that individualized care is the adequate response to the developmental needs of preterm babies and their families, a concern of the unit since its inception.

The healthcare professionals were certified in the program, which began at the unit on 11 June 2011. Since then a better support system was provided to both families and professionals through systematic observations that provide guidelines for care, based on interpretation of the signs that preterm babies show.

On 1 April 2015 the São João NIDCAP Training Center opened, the only

Portuguese-speaking center in the Federation, providing training to healthcare professionals working in NICUs.

We intend to present this journey and the benefits it brought to the Hospital São João's $\mathrm{NICU}$. 


\title{
OC47 - NICUs and family-centred care, from the leadership to the design, the results of a survey in Italy (by FCC Italian NICU study group)
}

\author{
Immacolata Dall'Oglio (Italy) ${ }^{1}$; Anna Portanova (Italy)2; \\ Emanuela Tízzo (Italy)3; Orsola Gawronsk (Italy)4; Gennaro Rocco \\ (Italy) $)^{5,6 ;}$ JM Latour (United Kingdom) ${ }^{7}$
}

\begin{abstract}
${ }^{1}$ University of Rome 'Tor Vergata', Professional Development, Continuing Education and Nursing Research Service, Bambino Gesù Children's Hospital, IRCCS; ${ }^{2}$ Department of Medical and Surgical Neonatology, Bambino Gesù Children's Hospital, IRCCS; ${ }^{3}$ Professional Development, Continuing Education and Nursing Research Service, Bambino Gesù Children's Hospital, IRCCS; ${ }^{4}$ University of Rome 'Tor Vergata', Professional Development, Continuing Education and Nursing Research Service, Bambino Gesù Children's Hospital, IRCCS; ${ }^{5}$ Centre of Excellence for Nursing Scholarship; ${ }^{6}$ Ipasvi Rome Nursing College; ${ }^{7}$ Clinical Nursing, School of Nursing and Midwifery, Faculty of Health and Human Sciences Plymouth University
\end{abstract}

Theme: Leadership, management, nursing education.

Keywords: Family-centred care, health care quality, Neonatal Intensive Care Unit (NICU) design, NICU environment.

Introduction: Family-centered care (FCC) in NICUs is related to staff culture and the organization of the unit.

Aim: To describe the organizational characteristics and services for families in Italian NICUs.

\begin{abstract}
Methods: This survey involved $105 \mathrm{NICUs}$ in Italy. The Italian version of the 'FCC in the NICUs: A Self-Assessment Inventory' developed by the Institute for FCC was sent to the nurse managers in January 2015.

Results: Forty-seven NICUs answered (49\%). The means of the NICU characteristics are number of beds: 20; newborns discharged/year: 331, of which very low birth weight infant: 68; unit's rooms: 3.7). The total mean score of the 10 areas explored by questionnaire was 2.6 (on 5 points Likert scale) for the 'status' and of 2.3 (on 3 points scale) for priority for change.
\end{abstract}

Conclusion: The results show an organizational lack, but also the consciousness of the need of change. Sharing new organizational strategies could be an important issue for the future. 


\section{OC48 - Hurtology: an online course}

\section{Casey Frechette (US) ${ }^{1}$}

\section{${ }^{1}$ USF St. Petersburg, Florida}

Theme: School health.

Keywords: Computer game, hurt, mental health, young people.

Background: The prevalence of anxiety and depression suggests a need to improve on the mental health education of young people. The school setting can provide a venue for offering such knowledge to adolescents.

Objectives: This study explored whether a video game enhances lessons designed to help adolescents become more receptive to learning about mental health concepts.

Methods: This study used a quantitative between-subjects design. The first group experienced a set of computer-based lessons. The second group received the same content, but also played a video game designed to reinforce topics explored in the other materials.

Results: The findings showed that game players demonstrated deeper learning on at least one measure.

Discussion: Helping adolescents develop better ways to understand the relevance of emotional health is a worthwhile endeavour.

Conclusions: New technologies can be used to improve learning and help young people become more receptive to addressing mental health concerns. 
Abstracts of posters 


\section{PO01 - Assessment of quality of life of children and adolescents with different types of cancer in all phases of treatment and its completion}

Efrosini Vlahioti (Greece) ${ }^{1}$; Pantelis Perdikaris (Greece) ${ }^{1}$;

Vasiliki Matziou (Greece) ${ }^{1}$

${ }^{1}$ Faculty of Nursing, National \& Kapodestrian University of Athens

Theme: Accreditation and quality improvement.

Keywords: Adolescents, cancer, children, quality of life.

Aim: The aim of this study was to evaluate quality of life of children and adolescents with different types of cancer in all phases of treatment and its completion.

Patients and methods: The sample of the study was 112 children and adolescents aged 8-20 years. Of these, 56 were new patients with any type of cancer who were receiving treatment and 56 were survivors who had successfully completed at least five years before treatment protocols for childhood cancer.

Results: For children and adolescents, new patients with any type of cancer, during the first measurement at baseline score on the scale for quality of life was 3.44 and 3.88, respectively, in the middle of treatment 3.36 and 3.89 , respectively, and with the completion of treatment 3.43 and 3.89 respectively.

Conclusions: The quality of life of the studied population was not significantly changed during the treatment and after its completion.

\section{PO02 - Clinical profile of children admitted to a paediatric intensive care unit due to acute clinical deterioration}

Claus Sixtus Jensen (Denmark) ${ }^{1,2} ;$ Hanne Aagaard (Denmark); Hanne Vebert Olesen (Denmark) 3; Hans Kirkegaard (Denmark) ${ }^{1}$

${ }^{1}$ Research Center for Emergency Medicine, Aarhus University Hospital; ${ }^{2}$ Aarhus University; ${ }^{3}$ Department of paediatrics, Aarhus University Hospital

Theme: Intensive care

Keywords: Critical care, critical illness, clinical deterioration, PICU

Background: There has been an increased number of critically ill patients admitted to paediatric departments. Only a few studies have described the various causes of unplanned admission to paediatric intensive care units (PICU) due to clinical deterioration. However, an understanding of the nature of illness is important to patient safety.

Purpose: This study described the frequency, clinical characteristics and outcomes of children who experience unplanned admission to a PICU due to clinical deterioration. 
Methods: A registry retrospective descriptive study describing and exploring life-threatening situations leading to unexpected transfers to PICU in hospitalised children. The study includes all paediatric departments in the Central Denmark Region.

Perspective: This study will provide knowledge to assist the research efforts to identify and improve the management of critical ill children in paediatric wards.

\title{
PO03 - Experience from a group of adolescents with severe allergy asthma treatment with omalizumab
}

\author{
Anne Marie Bro Hofbauer (Denmark) ${ }^{1}$; Lone Agertoft (Denmark) ${ }^{1}$ \\ ${ }^{1}$ Hans Christian Andersen Children's Hospital. Odense University Hospital
}

Theme: Complex health care and chronic disease management.

Keywords: Adolescents, allergic asthma, education, omalizumab.

Background: Evidence supports that group educational interventions improve selfperception, self-confidence and attack management in asthma care.

Aim: To evaluate education and structured dialogue in enhancing knowledge and insight in the asthma disease, treatment with omalizumab and social behaviour.

Method: A group of four 13-16-year-olds received education using question and answer cards, and were informed about the effects and adverse effects of omalizumab. The dialogue included life before and after, relation to family and friends, ability and lack of ability to perform physical activities, and dreams of the future. One week later there was a telephone interview.

Results: All four adolescents experienced a positive change in everyday life and ability to manage the asthma disease. Furthermore, they all experienced an enhanced physical ability. In the interview they reflected on their own disease and physical ability.

Conclusion: Adolescents with a chronic disease benefit from sharing thoughts, emotions and knowledge about their disease and treatment.

\section{P004 - Metasynthesis approach in paediatric nursing literature: a scoping review}

Joana Romeiro (Portugal) ${ }^{1}$; Sílvia Caldeira (Portugal) ${ }^{1}$
${ }^{1}$ Instituto de Ciências da Saúde, Universidade Católica Portuguesa

Theme: Professional issues

Keywords: Child, family, metasynthesis, paediatric care, qualitative studies.

Introduction: Metasynthesis is defined as the synthesis of qualitative research. Despite the growing interest in this approach in adult nursing literature, it is not clear how it has been used in paediatric nursing literature. 
Aims: To characterize the scientific production using metasynthesis in paediatric nursing literature.

Methods: A scoping review was conducted across eight international databases and three Portuguese nursing web journals.

Results: A total of 25 papers were included. First was published in 1998, most frequents phenomena were parenting and experiences of parents in several health contexts.

Metasynthesis $(n=10)$ and meta-meta-ethnography $(n=8)$ were most frequent. Noblit and Hare (1988) framework was most cited and sample ranged from 3 to 47 original studies.

Discussion: Metasynthesis research is providing evidence to nursing practice mostly in neonatal and intensive care regarding parenting.

Conclusions: Metasynthesis is being use in paediatric nursing, but in specific contexts and phenomena. Other qualitative research should be analyzed toward metasynthesis.

\title{
P005 - Diabetes nursing with clinical and organizational knowledge as aspects of diabetes management in children with type 1 diabetes
}

\author{
Vibeke Lauritzen (Norway) ${ }^{1}$; Ingrid Waldahl (Norway)'; \\ Ingjerd Gåre Kymre (Norway)² \\ ${ }^{1}$ UIT The Arctic University of Norway; ${ }^{2}$ University of Nordland
}

Theme: Complex health care and chronic disease management.

Keywords: Type 1-diabetes, glycemic control, paediatric diabetes specialist nurse, HbA1c, management.

The background for the study is former national publications showing low achievement for HbA1c in children with type 1-diabetes in Norway. Only 18\% achieved ISPADs goals for $\mathrm{HbA1c}$ in 2012. The aim of the study was to focus on nursing as a contribution in disease management and glycaemic control in children with diabetes.

The findings are from a qualitative study where 7 diabetes specialist nurses, who worked with children, participated in two focus groups. The interview-texts were analysed using qualitative content analysis.

The main findings were 'clinical challenges and contributions in diabetes nursing' and 'organisational challenges and contribution in diabetic nursing'.

The study's conclusion was that diabetes specialist nurses' contributions to chronic disease management in diabetes is more than achieving ISPADs goals for HbA1c. The nurses want less focus on Hba1c in consultations. Clinical and organizational skills together with coping and motivation are essential for how children can achieve treatment goals. 


\section{P006 - Cross cultural validation of the preterm oral feeding readiness assessment scale (POFRAS)}

Ilaria Orsenigo (Italy) ${ }^{1}$; Simona Serveli (Italy) ${ }^{1}$; Angela Cicconetti $(\text { Italy })^{1}$; Roberta Da Rin Della Mora (Italy) ${ }^{1}$

${ }^{1}$ G.Gaslini Children's Hospital

Theme: Cross-cultural nursing.

Keywords: Cross-cultural validation, oral feeding, preterm infant, scale, tube feeding.

Introduction: Preterm infants have to acquire neurological skills to begin breast or bottle feeding. The literature review suggested the need of a tool to assess the readiness of preterm infants for the transition from tube to oral feeding. Currently, there is not such a tool in the Italian context.

Aim: To perform the cross-cultural validation of POFRAS from English to Italian.

Method: We followed international guidelines to design and conduct the process (forward translations, synthesis, pilot test to assess the comprehensibility of the contents, back translations, synthesis).

Results: The Italian version was approved by the author of POFRAS.

Discussion: The validation process involved several professional figures (translators, paediatric nurses, a physiotherapist, a research nurse) to obtain conceptual and semantic correspondence between the two versions.

Conclusions: The Italian version of POFRAS is ready to undergo the statistical validation process, before it is used with the preterm infants.

\section{P007 - Is the 'children's and young people's audit policy tool' (CYAPT) useful to evaluate the variables of child and family-centred care? Comparison among nurses' perceptions from different countries}

Giulia Ottonello (Italy) ${ }^{1}$; Annamaria Bagnasco (Italy)2;

Simona Calza (Italy) ${ }^{1}$; Loredana Sasso (Italy) ${ }^{2}$

${ }^{1}$ G. Gaslini Hospital; ${ }^{2}$ University of Genoa, Department of Health Sciences

Theme: Accreditation and quality improvement

Keywords: Family-centred care, nursing practice, nurses perception of care, quality standards.

Introduction: Most of the nurses know the principles of family-centred care (FCC) and can 
define it. However, we need to investigate their real perceptions about this philosophy of care.

Aims: The aim of this research paper is to analyze how nurses from Gaslini Hospital perceive FCC practices. We use data taken from a questionnaire and compare these results with those obtained from other studies carried out in different countries.

Method: Qualitative study of data analysis from CYPAPT questionnaire.

Results: There is worldwide agreement about the features of FCC. Such agreement holds both for the positive sides, such as family individuality and trust in involving parents, and in weak points, such as structural and organizational problems and education paths for health professionals.

Conclusions: FCC is well rated worldwide from a theoretical point of view, but it needs further studies and multidisciplinary experimentations to be implemented in practice in the best way.

\title{
P008 - Perceptions of children and their parents about the pain experienced during their hospitalization and its impact on parents' quality of life
}

\author{
Vasiliki Matziou (Greece) ${ }^{1}$; Pantelis Perdikaris (Greece) ${ }^{2}$; \\ Efrosyni Vlahioti (Greece) ${ }^{3}$; Vasia Dimitriou (Greece) ${ }^{1}$; \\ Konstantinos Tsoumakas (Greece) ${ }^{1}$
}

${ }^{1}$ Faculty of Nursing, National \& Kapodestrian University of Athens; ${ }^{2}$ General Children's Hospital of Athens 'P \& A Kyriakou'; ${ }^{3}$ General Children's Hospital of Athens 'Agia Sophia'

Theme: Pain

Keywords: Adolescent, children, parents, perceptions, quality of life.

Background: In children and adolescents with cancer, as well as in their parents, the quality of life is affected due to pain experienced during their hospitalization.

Objectives: The aim was to report and assess paediatric and parental opinions about the pain the paediatric patients suffer.

Methods: The sample of the study consisted of 92 paediatric cancer patients, 159 paediatric patients with musculoskeletal problems and one of their parents with the Paediatric Pain Questionnaire and the PedsQL-Family Impact Module.

Results: Young patients reported higher acute pain scores than their parents $(z=-2.5$, $p=0.011 ; 99 \% \mathrm{Cl}: 0.008-0.013)$. Young patients with orthopaedic disorders had higher acute and chronic pain scores in comparison to their parents' reports $(z=-3.4, p=0.001$; 99\% Cl: $0.000-0.001$ and $z=-2.3, p=0.021 ; 99 \% \mathrm{Cl}: 0.017-0.025$ respectively).

Conclusions: The parental quality of life is affected especially when the pain is caused by life-threatening diseases, but it improves as the treatment ends. 


\title{
PO09 - Parenting promotion: recommendation during infant crying or tantrums and a child's feeding time
}

\author{
Graça Aparício (Portugal) ${ }^{1}$; Mara Marçalino (Portugal) ${ }^{1}$ \\ ${ }^{1}$ Polytechnic Institute of Viseu
}

Theme: Parenting/parenthood.

Keywords: Feeding time, infant cry, parenting, tantrums.

Introduction: Parenting role involves some stress, especially in infant cry/tantrums and during feeding time, leading to pursuit of nurse's counseling.

Objective: To identify evidence-based recommendations and best practice for parents coping with crying/tantrums and in the child's feeding time.

Methods: Systematic review of articles published among 2009-2014 in the following databases: CINAHL, Cochrane, MEDLINE, using descriptors and Boolean operators. Two reviewers assessed the studies' methodological quality and included 7 studies, one A evidence level, two B, and four expert opinions.

Results: Culturally congruent counseling is recommended by the reference nurse, accompanying parents by phone call/home care visit, especially if they are inexperienced. Providers should know the areas of online discussion to become aware of regarding current parental concerns, and instruct on children's development and advise positive attention, routines, clear boundaries, concrete and fair.

Conclusion: Early promotion of fair and consistent parenting minimizes the day-to-day difficulties and the child's future behavior.

\section{PO10 - A safe school day for a diabetic child}

\author{
Svetlana Lorvi-Talisainen (Estonia) ${ }^{1}$; Annika Härmits (Estonia) ${ }^{1}$ \\ Sirje Multram (Estonia) ${ }^{1}$ \\ ${ }^{1}$ Foundation for School Health Care in Tallinn
}

Theme: School health.

Keywords: Diabetes, networking, school.

Background: In the last five years, the number of children under the age of 18 with type 1 diabetes in Estonia has increased by $5 \%$ annually. Every school has approximately one to three diabetic pupils. School staff lack knowledge of the management of the disease.

Objective: To ensure the safety of diabetic children at school.

Method: It is a school-based intervention programme which is based on training, capacity building, networking, assessment surveys, support groups in 140 schools of Estonia.

Results: Every pupil with type 1 diabetes has a support person. Members of the network have clearly defined roles. Schoolchildren know how to help their diabetic peers. The diabetic child is capable of assessing their own health status (blood glucose, carbohydrate 
intake) and asking for help.

Discussion: Implementation of the project requires caring and commitment, rather than resources. Children with chronic illnesses must have equal access to education.

Conclusion: This project needs widening to be conducted in all schools where diabetic children study.

\section{PO11 - S.O.S. infant's crying! An educational path in a paedatric counselling context}

Federica Logrippo (Italy) ${ }^{1}$; Emanuela Berbotto (Italy) ${ }^{1}$; Marina

Remon (Italy)2; Anna Persico (Italy) ${ }^{1}$

${ }^{1}$ University of Turin; ${ }^{2}$ Pediatria di comunità, Asltol

Theme: Parenting/parenthood.

Keywords: Crying, empowerment, infant, parents.

Introduction: In Western societies, an infant's crying often causes anxiety in parents. Educational and empowerment paths of parenthood could be useful to overcome these difficulties (Hiscock 2004).

Aims: Design and implement a pilot test of an educational path with a group of infants' (0-3 months) parents to support them in the acceptance of their children's crying and develop coping strategies.

Methods: The pilot test is composed by two meeting with 8 parents in a paediatric counselling situation. It's based on an empowerment's model of parenthood. The tools are brainstorming and narrations; they are used to analyze intervention's needs and to accompany parents in accepting children's crying.

Results: The first narrations underline parents' need to take on the topic and to be valued in their parental role; from the second ones it comes out that the parents appreciate the project.

Conclusions: The pilot test was completed and appreciated by the parents.

\section{P012 - The Fuller's Infants Pain Assessment Scale utility in practice in the opinion of the nurses working in Tartu University Hospital}

Merle Seera Rn, Msc (Estonia) ${ }^{1}$

${ }^{1}$ Reet Kikas MD

Theme: Child protection and managing risk.

Keywords: Infants, pain management.

Aim: The aim of this study was to describe nurses' opinion on a Fuller's Infants Pain 
Assessment Scale utility in practice in Tartu University Hospital.

Methods: The research method was quantitative, empirical and descriptive, was carried out in Tartu University Hospital in the cardiac surgery, in the paediatric surgery and in the paediatric intensive care unit from 25 June to 23 September 2013. Participants $(n=21)$ used the scale for assessing the infants postoperative pain during three months and gave feedback about the scale utility in practice. An anonymous questionnaire was used to collect the data. The data was analysed using descriptive statistics and Fishers' test.

Results: The results showed the scale is useful for nurses' pain knowledge, improving the nurses' pain knowledge about identification of pain and pain documentation. It is suitable for teaching material to improve the nurses and student nurses' pain knowledges. However, it is not user friendly, is time consuming and completion requires considerable work.

\section{PO13 - Humanity in the neonatal intensive care unit}

Inger Jorun Danielsen (Norway) ${ }^{1}$; Ingjerd Gare Kymre (Norway) ${ }^{2}$

${ }^{1}$ UiT The Arctic University of Norway; ${ }^{2}$ University of Nordland

Theme: Ethical issues: dignity and humanity.

Keywords: Communication, developmental support, humanity, developmental support, interaction NICU nursing.

Nurses have a key role in delivering care based on developmental support where proximity and comfort is essential. Our work studies interactions between nurses, infants and parents.

1. Observations and interviews with 23 nurses - qualitative content analysis.

2. Interviews with 18 nurses - phenomenological descriptive analysis.

Five approaches were uncovered: (1) communication with the infant through senses, especially through hands; (2) grasping the infant's condition by combining sensory signs with measurable parameters; (3) promoting the infant's personality and integrity; (4) giving the infant access to parent and opposite; (5) enacting skin-to-skin care.

Humanity as supporting the infant's needs requires understanding the particular infant's cues and signals. There is a need to acknowledge nurses perceptions of SSC as a powerful mutual experience, which is existentially crucial while simultaneously laying the ground for developmental advantages. The two works call for an acknowledgement of the need for parents to be available to premature newborns.

\section{P014 - Paediatric post-operative pain assessment in day surgery}

\section{Emanuela Tiozzo Massimiliano Raponi (Italy) ${ }^{1}$}

${ }^{1}$ Bambino Gesù Children's Hospital, IRCSS, Rome, Italy

Theme: Child protection and managing risk 
Keywords: Children, pain assessment, satisfaction, and smartphone application.

Introduction: There are few studies that describe the usage of applications for pain assessment in the paediatric field. A pain cut-off $\geq 4$ is considered.

Objectives: To evaluate prevalence, incidence and intensity of paediatric pain at home at 24 hours, 5 days and 30 days post-surgery.

Methods: Post-operative pain was monitored with an app developed specifically for this project.

Results: In a population of 214 participants, at 24 hours the prevalence pain evaluation is $71 \%$ (intensity mean 2.3), at 5 days $48 \%$ (intensity mean 1.4 ) and at 30 days $24 \%$ (intensity mean 0.5). The incidence at 24 hours is $73 \%$, at 5 days $5 \%$, at 30 days $2 \%$.

Discussion: The pain app is a useful tool for pain measurement at home, facilitating monitoring and communication between parents and healthcare providers.

Conclusions: The pain application can be a valuable monitoring and decision-making tool for pain management.

\title{
PO15 - PBLS and primary school teachers: survey on training needs in first aid environment
}

\author{
Maria Cristina Tonello (Italy)1; Anna Persico (Italy)2; \\ Giovanni Borrelli (Italy)1 \\ ${ }^{1}$ University of Turin; ${ }^{2}$ Univesity of Turin
}

Theme: School health.

Keywords: Early defibrillation, cardiopulmonary resuscitation, lay, paediatric basic life support, school teachers.

Introduction: Only 15\% of European cases of CPR are performed by a witness. Prompt interventions can increase the person's chances of survival. Secular training programs are gaining even more importance.

Objective: Investigate primary school teachers' level of CPR training in two provinces of Piedmont (Italy).

Methods: We interviewed 667 teachers of which $82 \%$ took part in the study. A questionnaire of 24 questions was created to assess the level of expertise.

Results: 25 teachers had witnessed a student's cardiopulmonary arrest. Just 2 were able to perform a CPR on them. 38\% of the survey participants had been trained in PBLS. $87 \%$ of the educators stated they would not be capable of using an AED and $58 \%$ of them declared their schools are not equipped with AEDs.

Conclusions: This study shows how the majority of the teachers are not adequately trained and it proves the positive effect of a PBLS-D course. 


\title{
P016 - Endotracheal suctioning methods in newborns in Estonian children's intensive care units
}

\author{
Siret Läänelaid (Estonia) ${ }^{1}$; Annely Saareall (Estonia)2; \\ Raili Sommer (Estonia) ${ }^{2}$
}

${ }^{1}$ Tartu Health Care College; ${ }^{2}$ Tartu University Hospital

Theme: Child protection and managing risk.

Keywords: Endotracheal suctioning, newborn, neonatal intensive care unit.

Aim: To describe ETS methods in Estonian NICUs.

Method: Research sample $=67 \%$ of Estonian NICU nurses. 2011 data: survey protocol, questionnaire.

Results: Knowledge and experience on preparatory activity prior to suctioning varied: half carried out the appropriate hand hygiene; however, all put on gloves prior to suctioning. No one performed chest auscultation to comprehend pulmonary assessment. Most performed preoxygenisation prior to suctioning. Mistakes occurred using higher oxygen value. Most participants used saline prior to suctioning, completed the procedure in 15 seconds and made up to three passes per episode to remove tracheal secretions. All started suctioning process upon catheter resistance, but knew to advance the catheter to the carina and withdraw it $1 \mathrm{~cm}$ before applying suction. All used negative pressure only in withdrawing catheter from the ET. After suctioning, no nurse performed chest auscultation to assess the efficacy of the suctioning. Almost all assessed newborns' cardiopulmonary status before, during and after the procedure.

\section{PO17 - Infectional viral diseases that cause acute diarrhoea with infants and toddlers: nursing and prevention. A systematic review}

\author{
Airin Treiman-Kiveste (Estonia) ${ }^{1}$; Merge Kachan (Estonia) ${ }^{2}$ \\ ${ }^{1}$ Tartu Health Care College; ${ }^{2}$ Hospital of Järvamaa
}

Theme: Child protection and managing risk.

Keywords: Acute diarrhoea, infant, toddler, nursing.

Aim: The aim of the research was to describe infectional viral diseases that cause severe
diarrhoea with infants and toddlers, the ensuing problems and nursing activities, also
preventive measures in these cases.
English and Estonian language papers were examined. Scientific articles that were issued
in the period of 2005-2014 originated mainly from databases: MEDLINE, CINAHL and
PubMed. Papers were examined for methodological soundness before being included.
Acute infectious viral diarrhoea is a worldwide problem. Incidences of rotaviruses and
noroviruses, also hospitalisation of children due to dehydration and high temperature, will 


\title{
P018 - Safety road for children: knowledge and attitudes of parents in the use of child restraint systems
}

\author{
Helena Fernandes (Portugal); Graça Aparício (Portugal)²
}

${ }^{1}$ Centro Hospitalar de Trás-os-Montes e Alto Douro - Hospital Vila Real, Unidade de Neonatologia; ${ }^{2}$ Polytechnic Institute of Viseu/Health School

Theme: Child protection and managing risk.

Keywords: Road safety, child restraint systems, parents' knowledge.

Background: Correct use of a restraint system for children (CRS) from birth is an effective form of protection.

Objectives: To characterize parent's knowledge and attitudes in using CRS.

Methods: Cross-sectional study, held in a non-probabilistic sample of 112 parents of newborns, mothers mean age 30.37 years old $(S D=5.63)$. Parents completed a questionnaire, 24-48 hours after baby birth in Obstetrics and Neonatology services of a public hospital in Portugal.

Results: Mothers mostly had secondary level of education. In 54.5\% CRS was part of the 'layette baby' and, of these, $72.3 \%$ had already experimented it in the car. Only $15.2 \%$ reported having had training by nursing team during pregnancy. $97.3 \%$ intended to use the CRS, however only $47.3 \%$ would do it adequately. All recognize that CRS prevents serious injury, and $67 \%$ reported adequate knowledge.

Conclusions: Results indicate that knowledge and parental attitudes about the proper use of CRS remains insufficient.

\section{P019 - Developing a pain scale for infants in collaboration with clinical staff in the neonatal intensive care unit}

Tarja Pölkki (Finland) ${ }^{1}$; Anne Korhonen (Finland)2; Ulla Heikkinen (Finland) ${ }^{2}$; Anna-Kaija Palomaa (Finland)²; Seija Miettinen $(\text { Finland })^{2}$

${ }^{1}$ Institute of Health Sciences, University of Oulu; ${ }^{2}$ Department of Paediatrics and Adolescence, Oulu University Hospital

Theme: Multidisciplinary team working. 
Keywords: Collaboration, neonatal intensive care, infant, pain assessment, scale development.

Background: Pain assessment is unsystematic and only few nurses use pain scales in clinical practice. Poor compliance may indicate that scales are often inaccurate to assess specific behavior in vulnerable children.

Aims: The aim was to develop a feasible and sensitive enough pain assessment tool for neonates in close collaboration with clinical staff in the neonatal intensive care unit (NICU).

Methods: The development process of scale lasted for several years and it included many sessions of discussion and putting into practice the scale to test its adequacy.

Results: A multidimensional pain assessment scale called NIAPAS (the Neonatal Infant Acute Pain Assessment Scale) was developed. The scale was easy to administer and it allowed nurses to recognize any indications of neonate's pain.

Discussion: The development of a scale requires a long-term co-operation and multidisciplinary team working.

Conclusions: The NIAPAS is recommendable to assess acute pain in preterm and full-term infants.

\title{
PO20 - Parental suggestions for developing pain management in neonatal intensive care units
}

\author{
Anna-Kaija Palomaa (Finland) ${ }^{1}$; Anne Korhonen (Finland) ${ }^{1}$; \\ Tarja Pölkki (Finland) ${ }^{2}$
}

${ }^{1}$ Department of Paediatrics and Adolescence, Oulu University Hospital; ${ }^{2}$ Institute of Health Sciences, University of Oulu

Theme: Parenting/parenthood.

Keywords: Infant, neonatal intensive care, pain management, parents, participation.

Background: Neonates are likely to experience numerous painful procedures in neonatal intensive care units (NICUs). Parents have expressed a wish to be more involved in their infants' pain alleviation.

Aims: The aim of this study was to describe parents' suggestions for the development of neonatal pain management in hospital.

Methods: Informants were parents $(n=140)$, whose children were in care in the NICUs of Finland. Data were collected through the questionnaires, and the open-ended data were analyzed using inductive content analysis.

Results: Parents' suggestions for developing pain management consisted of six main categories: developing counselling, changing nursing practices, providing emotional support, considering parent-oriented practices, changing the attitude of the staff and increasing social support.

Discussion: It is essential to provide sufficient counseling to parents related to their child's pain management.

Conclusions: Pain management practices need to change towards more family-centered care in the Finnish NICUs. 


\title{
P022 - Children's satisfaction with the diabetes nursing consultation
}

\author{
Anabela Pires (Portugal)1; Graça Aparício (Portugal)²; João Duarte \\ $(\text { Portugal })^{2}$ \\ ${ }^{1}$ Unidade Local de Saúde do Nordeste, E.P.E.; ${ }^{2}$ Escola Superior de Saúde de Viseu - \\ Instituto Politécnico de Viseu
}

Theme: Nursing education, management and leadership.

Keywords: Children, consultation, diabetes, nursing, satisfaction.

Introduction: Therapeutic education and the monitoring of child/family with diabetes to allow an exchange of knowledge, the maximum control and the best management in this new condition.

Objective: To determine the children's satisfaction level with the diabetes nursing consultation.

Methods: Cross-sectional and descriptive study. Non-probability sample comprising 135 children aged 8-18 years old (Average: 13.45; SD=2.83) who attend the diabetes consultation in six Portuguese public hospitals. An adapted version of the Escala de Satisfação dos Utentes (Users' Satisfaction Scale) with the Diabetes Nursing Consultation (Chaves et al 2012) was used.

Results: The 135 children showed a global satisfaction average rate of $87.4 \%$, that was from $91.06 \%$, in the 'Initial assessment' dimension, 93.56\% regarding the 'guidelines' and 79.55\% in 'relationship/communication'.

Conclusion: The adequacy of strategies in diabetes consultation promotes a greater involvement of children, independence in health care, better adherence and management in therapeutic procedures, thus resulting in higher satisfaction.

\section{PO23 - Behavioural therapy via a video conference}

\author{
Judy Grejsen (Denmark) ${ }^{1}$; Lone Aaslet (Denmark); \\ Nanette Debes Mol (Denmark) ${ }^{1}$; Liselotte Skov (Denmark) ${ }^{1}$ \\ ${ }^{1}$ Herlev Hospital
}

Theme: Therapy and technology

Keywords: Behavioural therapy, telemedicine, tics, Tourette syndrome.

Methods: Since December 2014, 10 patients have participated and finished the therapy. The first and last session took place at the Tourette clinic and sessions 2-11 were offered via video conference. Before and after BT, Yale Global Tics Severity Scale and PedsQI (Quality of Life) were used to assess the effectiveness of BT. We compared these patients with 10 patients with traditional BT. 
Results: Both in the group with video conference BT and in the group with traditional BT, we found a decrease in motor, vocal, and total tics and global severity score. The quality of life increased in both groups. These effects were not statistically significant different between the groups.

Conclusion: The effectiveness of BT via video conference seems to be as effective as traditional BT. If further analyses confirm these results, we will offer video conference treatment to all the patients who find it difficult to meet physically.

\section{P024 - Paediatric nurse reception (PNR) at the children's emergency department in Gothenburg}

Sigrid Lang (Sweden) ${ }^{1}$; Samy Sebraoui (Sweden) ${ }^{2}$; Anna-Pia Wentzel (Sweden)2; Malin Ekström (Sweden) ${ }^{1}$

${ }^{1}$ Queen Silvias chlidrens hospital; ${ }^{2}$ Queen Silvias childrens hospital

Theme: Accreditation and quality improvement.

Keywords: Paediatric nurse reception.

Background: The children's ER receives 50,000 patients yearly. The majority of the patients have mild discomforts. Can these patients be treated by a paediatric nurse?

Aim: How satisfied are the families? What is the revisiting frequency?

Methods: The pilot study was performed under two weeks in October 2015. A paediatric nurse performed a clinical evaluation and took appropriate action based on condition. The nurse filled in the study protocol. Interviews were made by telephone.

Result: The PNR had 131 patients during the time of the study. $12 \%$ of the patients were transferred to the emergency department. Two out of the 131 patients returned to the ER within 14 days. Parents of children who were treated at the PNR were very satisfied.

Conclusion: The revisiting frequency was very low.

\section{P025 - Catastrophe simulation through an interactive board game}

Sigrid Lang (Sweden) ${ }^{1}$; Younis Khalid (Sweden)";

Anna-Pia Wentzel (Sweden)1; Malin Ekstrom (Sweden)1;

Helena Bidås (Sweden) ${ }^{1}$

${ }^{1}$ Queen Silvia's Children Hospital, Gothenburg

Theme: Multidisciplinary team working.

Keywords: Catastrophe simulation, catastrophe training.

Aim: Catastrophes are rare, which means that the habit of dealing with them is small and all while there are high demands on well-functioning work routines. The purpose is to increase 
the participants' experience and knowledge about catastrophes.

Methods: The exercise consisted of an interactive board game. The board game represents a map of the ER. Personnel, patients and others were illustrated as game cards. The participants were introduced to a specific situation. The game was played in real time.

Result: The game has been used in regional paediatric educations. The evaluation showed that the game is realistic, educational and has given the participants an increased knowledge and security for potential future catastrophes. The physician class gave the game a 5,8/6 points.

Conclusion: Simulation through interactive role play is considered to be a valuable and educational way of preparing for a catastrophe.

\title{
PO26 - Physical activity - young people's behaviours in Vila Nova de Famalicão
}

\author{
Ilda Fernandes (Portugal) ${ }^{1}$; Manuela Martins (Portugal) ${ }^{1}$; \\ Bárbara Gomes (Portugal)ín Luísa Andrade (Portugal) ${ }^{1}$; \\ Ana Silva (Portugal) ${ }^{1}$
}

${ }^{1} E S E P$

Theme: Physical activity

Keywords: Adolescent, health behaviours, physical exercise, social determinants.

\begin{abstract}
Physical activity in adolescence is of major significance considering body, emotional and behavioural changes. A quantitative, descriptive and transversal study was performed to analyse the physical activity of adolescents from a school community in Vila Nova de Famalicão. A self-administered questionnaire was applied to 1614 adolescents attending secondary and higher education in the academic year 2013/2014, aged between 14-21 years. From total participants, 56.9\% were female and $86.5 \%$ attended secondary school. From the participants engaged in physical activities over the previous week, during 20 minutes, with an increase in sweating and/or in respiratory frequency, 24.9\% referred twice and $12.7 \%$ did not engage in any activities; at least 30 minutes duration, with no visible physiological changes, $10.4 \%$ with daily activities and $41.9 \%$ with no activities and $19.3 \%$ (twice) and $7.6 \%$ (daily) refereed activities to strengthen muscles. Physical activity needs to be promoted to achieve physical and emotional wellbeing among young people.
\end{abstract}

\section{P027 - Road safety - young people's behaviours in Vila Nova de Famalicão}

Ilda Fernandes (Portugal) ${ }^{1}$; Manuela Martins (Portugal) ${ }^{1}$;

Luísa Andrade (Portugal) ${ }^{1}$; Eliana Machado (Portugal) ${ }^{1}$

${ }^{1}$ ESEP

Theme: Accidents 
Keywords: Adolescent, safety, social determinants, health behaviours.

Health problems caused by the inadequacy of road safety measures have increased significantly and represent the main cause of morbidity and mortality among young people. A quantitative, descriptive and transversal study was performed contributing with information on safety and violence behaviours of adolescents from a school community in Vila Nova de Famalicão. A self-administered questionnaire was applied to 1,614 adolescents attending secondary and higher education in the academic year 2013/2014, aged between 14-21 years. From total participants, $56.9 \%$ were female and $86.5 \%$ attended secondary school. Results showed that $34.5 \%$ travelled by motorcycle and $65.8 \%$ by bicycle, without a safety helmet. The young drivers (3.6\%) did not always used the safety belt and $4.8 \%$ were driving after alcohol intake. Data shows a significant percentage of young people having road risk behaviours, highlighting the need for intervention in this area.

\title{
P028 - Adolescents with congenital heart disease - transition from paediatric to adult care units
}

\author{
Fernanda Carvalho (Portugal); \\ Figueiredo (Portugal) ${ }^{1}$
}

${ }^{1}$ Escola Superior de Enfermagem do Porto

Theme: Transition of care.

Keywords: Adolescents, congenital heart disease, transition.

Most children with congenital heart disease will need specialized medical care for life.

Programmes to promote transition from children's to adult care services must happen at any time and have been developed worldwide.

The purpose of this presentation is to identify the expectations of adolescents, their parents and healthcare team about the transition to adult care and to describe current practice of transition in Portugal.

A questionnaire was created, based on published evidence and international guidelines, with three versions: adolescents, parents, and healthcare professionals. It was validated by a panel of experts to evaluate the relevance and simplicity of the questions and to analyse its adequacy to the study purposes.

Questionnaires have been applied to adolescents, parents and healthcare professionals in the outpatient services of the paediatric cardiology reference centres in Portugal.

Results of this study will allow the planning of a transition program with input from the three groups involved. 


\title{
P030 - Child abuse: perception and teacher training
}

Isabel Bica (Portugal)i; Sandra Cunha (Portugal)²; José Costa (Portugal) ${ }^{1}$; Madalena Cunha (Portugal) ${ }^{1}$; Carlos Albuquerque (Portugal)룰 Margarida Reis Santos (Portugal) ${ }^{3}$

${ }^{1}$ CI\&DETS - Health School of Viseu - Polytechnic Institute of Viseu; ${ }^{2}$ Centro Hospitalar Cova da Beira, Covilhã; ${ }^{3}$ ESEP - Escola Superior de Enfermagem do Porto

Theme: Child protection and managing risk.

Keywords: Child abuse, education/training for health, school, teachers.

Introduction: On child abuse the protection of children requires cooperation between health and education professionals.

Objectives: To relate the sociodemographic and training context variables with the perception of teachers about child abuse.

Methods: A descriptive-correlational and cross-sectional study. A sample of 172 teachers of the 1st cycle, selected by convenience. Questionnaire with sociodemographic characterization, training and perception about child abuse.

Results: Participants with an average age of 45 and average experience of 25.7 years $(S D=6,83)$. Expertise in the related area-34,3\% acquired in the training base and $16.3 \%$ in further training. Only $15.7 \%$ knew the 'guideline for education professionals in addressing mistreatment situations...'. The majority considered the training important (98\%). Teachers with experience of more than 32 years considered it very important.

Conclusion: The predictors of perceived mistreatment were: professional experience $(p=.045)$, training and guidelines acknowledgement $(p=.002)$. This indicates a need for training, from the health team to teachers seeking their empowerment.

\section{P031 - Preventive knowledge, attitudes and behaviours about AIDS in adolescent Portuguese inserted in a non-urban environment}

\author{
Assunção Dores Laranjeira De Almeida (Portugal) ${ }^{1}$ \\ ${ }^{1}$ Aveiro University
}

Theme: Ethical issues, dignity, humanity.

Aim: The main objective of this investigation was to identify preventive knowledge, attitudes and behaviors about AIDS on the teenagers which are studying at the secondary school inserted in a non-urban environment.

Therefore a descriptive study was developed with a sample of 371 teenagers. The instrument of the collection of data adopted was made on the bases of the conceptual 'Health Belief Model'. 
The most significant results allowed us to conclude that the large majority of adolescents recognize AIDS as a normal disease. The most commonly reported method of transmission was sexual contact with a person already infected. 52.54\% of the interviewees mentioned having taken preventive measures. Although $42.01 \%$ of them have done nothing.

The majority considered that condoms were the safest method and showed an intention of use in all circumstances.

\title{
P032 - Look at me - who do you see? What are the impacts of Facebook profiles on the emotional wellbeing of young people?
}

\author{
C. Mackrell (United Kingdom)ํㅜㄹ C. Hall (United Kingdom) ${ }^{1}$
}

${ }^{1}$ School of Health Sciences, University of Nottingham

Theme: Ethical issues: dignity and humanity.

Keywords: Dignity, emotional wellbeing, Facebook, social media, young people, social media.

Social media is a critical form of communication for young people. For those requiring nursing care, and physically removed from usual communities, impressions of social media may be particularly influential.

To explore the impact Facebook has on wellbeing this study evaluated young people's perceptions of Facebook-style profiles using Likert scales and open questions. A total of 40 students situated within Erikson's (1968) 'ego identity versus role confusion' stage of development participated.

Findings identified that these young people were influenced by profile content viewed in a Facebook style, and that negative social comparisons they frequently made reduced their self-esteem. This has implications for young people and for CYP nurses.

To offer best practice for young people, nurses must understand the importance of social media and yet acknowledge potential risks. New student nurses of a similar age should be professionally aware to ensure respect and dignity in judgments which may affect patient care.

Erikson E (1968) Identity: Youth and Crisis. Norton, New York NY. 